\begin{tabular}{|c|l|}
\hline Title & $\begin{array}{l}\text { Millennial-scale East A sian Summer Monsoon variability recorded in grain size and provenance of mud belt sediments } \\
\text { on the inner shelf of the East China Sea during mid-to late Holocene }\end{array}$ \\
\hline Author(s) & Wang, Ke; Zheng, Hongbo; Tada, Ryuji; Irino, Tomohisa; Zheng, Y an; Saito, Keita; Karasuda, A kinori \\
\hline Citation & $\begin{array}{l}\text { Quaternary international, 349, 79-89 } \\
\text { https://doi.org/10.1016/.quaint.2014.09.014 }\end{array}$ \\
\hline Issue Date & 201410-28 \\
\hline Doc URL & http://hdl.handle.net/2115/57752 \\
\hline Type & article (author version) \\
\hline File Information & QI Ke WANG.pdf \\
\hline
\end{tabular}

Instructions for use 


\title{
Millennial-scale East Asian Summer Monsoon variability recorded in grain size and provenance of mud belt sediments on the inner shelf of the East China Sea during Mid-to Late Holocene
}

\author{
Ke Wang $^{a}$, Hongbo Zheng ${ }^{b}$, Ryuji Tada ${ }^{c}$, Tomohisa Irino ${ }^{d}$, \\ Yan Zheng ${ }^{e}$, Keita Saito ${ }^{c}$, Akinori Karasuda ${ }^{c}$
}

${ }^{a}$ Graduate School of Environmental Science, Hokkaido University, N10W5 Sapporo, Hokkaido, Japan

b School of Geographical Science, Nanjing Normal University, No.1, Wenyuan Rd., Xianlin University District, Nanjing, China

${ }^{c}$ Department of Earth and Planetary Science, Graduate School of Science, The University of Tokyo, 7-3-1 Hongo, Bunkyo-ku, Tokyo, Japan

${ }^{\mathrm{d}}$ Faculty of Environmental Earth Science, Hokkaido University, N10W5 Sapporo, Hokkaido, Japan

${ }^{\mathrm{e}}$ Institute of Vertebrate Paleontology and Paleoanthropology, Chinese Academy of Sciences, No.142 Xizhimenwai Str., Beijing, China

\section{Abstract}

The response of the monsoon climate on the inner shelf of the East China Sea (ECS) to abrupt climate changes events within the monsoonal Yangtze River drainage is contentious. Repositioning of the monsoon front is thought to have been responsible for the changes in hydroclimate over the Yangtze River drainage, which has exerted great impact on the sedimentation of the inner shelf of the ECS during the Holocene. Here, we present high-resolution analyses of grain size and provenance of the sediments from core MD06-3040 recovered from the inner shelf of the ECS during MD155-Marco Polo II-IMAGES XIV cruise. Significant variability occurred in the core MD06-3040 with notable decrease in East Asian Summer Monsoon precipitation (presumably drought events) at 6000 BP, 5300 BP, 4500 BP, 3700-3300 BP, 2200 BP, 1400-1300 BP, and 800-600 BP, which coincide with the $\delta^{18} \mathrm{O}_{\mathrm{w}}$ record in the northern ECS and stalagmite $\Delta \delta^{18} \mathrm{O}_{\mathrm{sp}}$ records from southern China. Similar patterns of these temporal variations suggest that the Yangtze River discharge associated with EASM precipitation has been a dominant control on the sedimentation on the inner shelf of ECS.

Keywords: East Asian Summer Monsoon, Yangtze River, Holocene, East China Sea

\section{Introduction}

The sedimentary successions are an archive of past climatic and environmental changes. The characteristics of the sedimentary record are controlled by the sediment supply, sediment dispersal 
process governed by the water and sediment discharges, tides, waves, and coastal currents, as well as the area available for sediment accumulation. The inner shelf of East China Sea (ECS) is of primary importance owing to massive inputs of terrestrial materials from the Yangtze River, one of the largest rivers in the world in terms of sediment load and freshwater discharge (Milliman and Meade, 1983; Milliman et al., 1985; Milliman and Syvitski, 1992) with complex ocean circulation on the shallow (<130 m) and broad (500 km) ECS shelf (Qin, 1979; Qin, et al., 1987). The study of the river-derived sediment dispersal, transport, and deposition is crucial to understand more thoroughly sedimentary processes on the inner shelf of ECS, and thus receives considerable attention.

Geological and geophysical investigations have demonstrated that the mud belts elongated along coast on the inner shelf of ECS are continuous with high sedimentation rates (Saito et al., 2001; Hori et al., 2001, 2002; Xiao et al., 2004, 2006; Liu et al., 2002, 2007; Zheng et al., 2010). The detailed characteristics of this elongated inner-shelf mud belt were documented by Liu et al. (2006, 2007), which presented a mud belt of $800 \mathrm{~km}$ extending from the Yangtze estuary southward off the Zhejiang and Fujian coasts into the Taiwan Strait based on high-resolution CHIRP seismic profiles. The development history of these Yangtze-derived sediment was proposed and the preliminary sediment budget have been discussed (Saito et al., 2001; Hori et al., 2002; Xiao et al., 2006; Liu et al., 2006; 2007; Liu et al., 2007; Zheng et al., 2010). The previous research summarized that transport mechanisms and deposition of sediments in the mud belts are mainly affected by sedimentological conditions associated with the dynamic hydrological regime such as sediment load, river discharge, and water mixing driven by the intensity of currents, tides, and waves. The extracted information from this region should indicate the possible influence of the sediment load and water discharge from the Yangtze River during high runoff in summer. Previous study has revealed that intervals characterized by lower magnetic mineral concentrations and higher coercivities are identified in the core sediment of inner shelf of ECS indicating the relationship between magnetic properties and paleoclimatic parameters related to East Asian Summer Monsoon (EASM) (Zheng et al., 2010). On the other hand, abrupt increases in mean grain size of the fine silt in the core sediment from the inner shelf of ECS were suggested to reflect sudden strengthening of the Chinese Coastal Current (CCC), which was driven by the East Asian Winter Monsoon (EAWM). In this case, the grain-size variations were interpreted as a proxy for the EAWM (Xiao et al., 2006; 2010). As the depositional history of the mud belt system off the Zhejiang-Fujian Coast has been controlled by the Yangtze River discharge 
and various ocean circulation system in the ECS, the sediment cores taken from this area sould be useful to understand a complex interplay between hydrological cycles of the Yangtze River and re-distribution of sediment on the inner shelf. The detrital grain size (Xiang et al., 2006; Xiao et al., 2006), clay minerals (Xu et al., 2009; Liu et al., 2010), magnetic parameters (Zheng et al., 2010) have been examined to reconstruct variations in fluvial processes, sea levels, and temperature/precipitation conditions. Despite a large amount of data, our knowledge on the sediment dispersal system on the inner shelf of ECS has been limited due to relatively short penetration depths of piston and gravity cores as well as limited radiocarbon dates.

Here, we present the results of analyses for grain-size and quartz characteristics in the sediment cores MD06-3039/3040 collected from the inner shelf of ECS spanning the whole Holocene in order to discuss the alongshore transport of the Yangtze-derived sediment, development of sedimentary facies in situ as well as potential sediment provenance. The variability in the Yangtze River discharge and sedimentation process of river-derived sediments associated with temporal changes in EASM during the Holocene has been illustrated.

\section{Regional setting}

The Yangtze River, also called Changjiang, has the largest $\left(1,800,000 \mathrm{~km}^{2}\right)$ drainage area and the longest $(6300 \mathrm{~km})$ length in Asia, and ranks fifth globally in terms of water discharge and fourth in terms of sediment load. The Yangtze River discharges approximately $960 \times 10^{9} \mathrm{~m}^{3}$ of freshwater into the ECS annually. Although annual sediment load has been reduced from $0.5 \times 10^{9} \mathrm{t} / \mathrm{y}$ in the 1960 s to $0.34 \times 10^{9} \mathrm{t} / \mathrm{y}$ in the $1990 \mathrm{~s}$ because of dam construction and water consumption, the Yangtze River is still predominant sediment supplier to the delta and coastal areas (Milliman and Meade, 1983; Milliman et al., 1985; Chen et al., 1988; Milliman and Syvitski, 1992; Yang et al., 2002). The sediment load by the Yellow River transported into the ECS is estimated at $<0.02-0.16 \times 10^{9} \mathrm{t} / \mathrm{y}$ (Demaster et al., 1985; Su and Huh, 2002). Contributions from other local rivers, such as Qiantang River, Min River, Ou River, and Jiao River in the coastal areas of Zhejiang and Fujian are $0.007 \times 10^{9} \mathrm{t} / \mathrm{yr}, 0.006 \times 10^{9}$ $\mathrm{t} / \mathrm{yr}, 0,003 \times 10^{9} \mathrm{t} / \mathrm{yr}, 0.001 \times 10^{9} \mathrm{t} / \mathrm{yr}$, respectively (Deng et al., 2006). The total sediment supply from

the coastal rivers including Yangtze River into the ECS is estimated to be $0.6-0.7 \times 10^{9} \mathrm{t} / \mathrm{y}$. Other major potential sources such as the coastal erosion of the abandoned Yellow River Delta, Taiwan Island, and atmospheric aerosols could account for about $37 \%$ of total input to the ECS (Tong and 
Cheng, 1981; Zhang and Liu, 2002).

The water masses in the ECS are characterized by various components, including Changjiang Dilute Water (CDW), Chinese Coastal Current (CCC), Taiwan Warm Current (TWC), Kuroshio Current (KC), and are influenced by tidal mixing and atmospheric forcing (Chang and Isobe, 2003; Liu et al., 2003; Lee et al., 2003). As is shown in Fig.1, the CCC, including the Jiangsu Coastal Current (JCC) in the north and the Zhejiang-Fujian Coastal Current (ZFCC) in the south, flows south to southwestward along the Chinese coast. The saline and warm TWC flows northeastward along the $50 \mathrm{~m}$ isobath and intrudes into the submerged river valley off the Yangtze River. The warm and salty Kuroshio Current (KC) travels northward along the continental shelf break (Yang et al., 1984; Chen et al., 1986; Yang, et al., 1992; Chang and Isobe, 2003).

Hydrographic and current meter data describing the spatial and temporal structure of the Yangtze River discharge over the inner and middle continental shelf of ECS show that in summer during high runoff, the freshwater discharge near the estuary of the Yangtze exhibited a bimodal distribution with the freshest water extending in a band to the south along the coast, and a relatively shallow, low salinity plume-like structure extending offshore on average towards the northeast(Beardsley et al., 1985).The thin jet theory of Robinson and Niiler(1967) also suggests that the strength and orientation of the river discharge are important. During the summer when winds are relatively weak and river discharge high, the theory implies that the structure of the discharge plume over the inner shelf will be strongly influenced by the inertia of the discharge, vortex stretching, and bottom friction. The enormous amounts of sediment load carried by the Yangtze River sustain delta and coastal ecosystems. Accordingly, almost half of the Yangtze-derived sediments accumulate in the subaerial delta and estuarine system. The rest are deposited mainly during the flood season in the nearshore subaqueous deltaic and the inner shelf systems of the ECS (McKee et al., 1983; Li et al., 1986, 2001). The largest mud belt was formed on the inner shelf of the ECS, within a narrow band stretching from the subaqueous delta of the Yangtze River southwestward to the Taiwan Strait (Liu et al., 2007). Two major types of sediments on the ECS shelf system have been recognized as shown in Fig.2: the Yangtze River-derived mud-dominated sediments and the relict sandy sediments deposited during the Late Pleistocene low sea level stands (Qin et al., 1979, 1987). The transported fine grained sediments formed an along-shelf clinoform nearby Zhejiang-Fujian coast, called the Zhejiang-Fujian Mud Wedge (ZFMW) (Liu, et al., 2007). The grain size distributions of mud belt sediments have been 
described by Qin (1979) as clayey-silt unimodal distributions of grain size representing sediments derived from a single source, the Yangtze. The (quasi-) bimodal distributions of grain size in the mud belt margin indicate a combination of fine-grained Yangtze River sediment and coarse grained relict sediments, that could be representative of the energetic and erosive physical conditions that serve to resuspend and transport the Yangtze-derived fine-grained sediment southward along the inner shelf, exposing coarse relict and transgressive sands beneath, or might be affected by another provenance, such as local river input (Dagg et al.2004; Liu et al, 2006).

The sediment sequence in the Yangtze estuary and mud belt areas (Christie Blick and Driscoll, 1995; Chen et al., 2003, 2004, Liu and Milliman, 2004, Liu et al., 2007) consist of the post-glacial transgressive surface (TS) and transgressive systems tract (TST) overlain by the subsequent high stand system tract (HST) separated with the maximum flooding surface (MFS). TSs are found at shallower ( -50 to $-58 \mathrm{~m})$ or deeper $(-70$ to $-90 \mathrm{~m})$ depth below present sea level, which were considered to be formed during Melt Water Pulse (MWP) -IB at 11500 BP and MWP-IA at 14200 BP, respectively. The thin TST deposit has been found only in those profiles with TS deeper than -70 m (after the MWP-1A transgression). For those profiles with shallower TS, there was no TST. No TST apparently developed after the MWP-1B transgression at $11500 \mathrm{BP}$, as the rate of relative sea-level rise increased, and distal parts of the shelf became sediment starved because the depocenter of sedimentation moved landward (Liu, 2004; Liu et al., 2007). Historically, the Yangtze-derived sediment began to be transported southward after the middle Holocene sea-level highstand, before $7000 \mathrm{BP}$ as estimated from the ${ }^{14} \mathrm{C}$ dating of the bottom of HST (Li et al., 1986; Liu et al., 2007). This HST body could correspond to the ZFMW. The top of HST is also clearly differentiated in seismic profiles and several sediment cores. The topset formed in the recent 2000 years has been considered as a result of an accelerated progradation rate, reflecting an increase in sediment production due to widespread human interference and/or decrease in deposition in the middle reaches of Yangtze drainage related to anthropogenic channel stabilization and climatic cooling (Hori et al., 2001; Liu et al., 2007).

\section{Material and methods}

\subsection{Cores MD06-3039 and MD06-3040}

During the IMAGES MD155-Marco Polo cruise II by R/V Marion Dufresne in 2006, two cores MD06-3039 and MD06-3040 were recovered from the mud belt off the Zhejiang-Fujian coast on the 
inner shelf of ECS. MD06-3039 core $\left(27^{\circ} 43.36^{\prime} \mathrm{N}, 121^{\circ} 46.91^{\prime} \mathrm{E}\right)$, with a length of $8.11 \mathrm{~m}$, was recovered by a giant gravity corer $(25 \mathrm{~cm} \times 25 \mathrm{~cm} \times 12 \mathrm{~m})$ at a water depth of $47 \mathrm{~m}$. MD06-3040 core was collected using a giant piston corer (10 $\mathrm{cm}$ internal diameter) at approximately the same location $\left(27^{\circ} 43.36^{\prime} \mathrm{N}, 121^{\circ} 46.88^{\prime} \mathrm{E}\right)$ and a water depth of $47 \mathrm{~m}$, with $19.36 \mathrm{~m}$ recovered. Judging from the subbottom profile, MD06-3040 recovered the sediment above a strong reflector at about -67 m below sea level (Fig. 3f).

Stratigraphic correlation between the cores MD06-3039 and MD06-3040 was evaluated visually based on pattern matching and cross-correlation of the magnetic susceptibility profiles (Fig. 3b, 3c), which enabled us to project the stratigraphic position (depth) of MD06-3039 to the depth of MD06-3040. Three lithostratigraphic units for core MD06-3040 were defined, primarily based on visual description with reference from the Marco Polo report of 2006. Magnetic susceptibility was measured onshore. Each lithological unit is described below.

\subsubsection{Unit 1 (U1, 19.3-18.3 m)}

U1 consists of dark grey coarse, moderately sorted silt, interbedded with thin layers of coarse sand, and rich in bivalve shell fragments. Some of the muddy beds are characterized by dark gray rhythmic intercalations of millimeter to centimeter scale layers of coarse silt, exhibiting wavy bedding. Above $\mathrm{U} 1$, an abrupt decrease appears in magnetic susceptibility, illustrating the coarsening of the grain size of the core.

\subsubsection{Unit $2(\mathrm{U} 2,18.3-15.86 \mathrm{~m})$}

$\mathrm{U} 2$ consists of dark gray medium silt interbedded with fine sand thin layers or ripples with some bioturbation. Wavy and lenticular beddings are the typical depositional structures, and bivalve shell fragments are scattered.

\subsubsection{Unit $3(\mathrm{U} 3,15.86-0 \mathrm{~m})$}

U3 is primarily dominated by yellow to olive gray fine silt, intercalated with fine sand lenses. Disconformities occur with steep slope and irregular surfaces between 3.00-3.18 $\mathrm{m}$ and 3.20-3.33 m and slightly brownish silty material with higher water content inserted in olive gray clay. At $235 \mathrm{~cm}$,

a gastropod, similar to Turritella, with diameter of approx. $1 \mathrm{~cm}$ has been found. The top $0-2 \mathrm{~cm}$ of 
the core was not preserved.

\subsection{Age model}

Using the common stratigraphic framework established between MD06-3039 and MD06-3040, the age model for cores MD06-3040 was constructed using nine $\mathrm{AMS}^{14} \mathrm{C}$ dates of bivalve shells. Five shell samples were collected from core MD06-3039 and four obtained from core MD06-3040. These nine shell samples were pretreated and converted to graphite targets at State Key Laboratory of Isotope Geochemistry, Guangzhou Institute of Geochemistry, Chinese Academy of Sciences. The graphite analysis for radiocarbon was performed at the State Key Laboratory of Nuclear Physics and

Technology, Peking University. AMS ${ }^{14} \mathrm{C}$ dates were converted to calendar years using Calib 7.0 (Stuiver et al., 1993, 1998), where Marine 04 was used for the calibration data set, which included a constant average global reservoir age of $400 \mathrm{yr}$ (Hughen et al., 2004). The summary of the AMS ${ }^{14} \mathrm{C}$ dates are given in Table 1.

\subsection{Grain-size analysis}

Selected 478 sediment samples from core MD06-3040 with a stratigraphic interval of $4 \mathrm{~cm}$ were measured for grain size distribution using Beckman Coulter LS 230 laser diffraction particle size analyzer at State Key Laboratory of Marine Geology, Tongji University, China. The measured grain-size range was between 0.375 and $2000 \mu \mathrm{m}$. The reproducibility is better than 2 vol. $\%$ for each grain-size class based on the previous controlled trial. Approximately $150 \mathrm{mg}$ of sample was treated with $10 \%$ hydrogen peroxide solution under a heated water bath at $60{ }^{\circ} \mathrm{C}$ for 8 hours to remove organic matters, and acidified with 20 vol. \% acetic acid solution at room temperature for 8 hours to remove biogenic carbonates. The biogenic silica removal was not necessary since opal content of selected samples from core MD06-3040 were less than $3 \%$. After each treatment step, the samples were rinsed by distilled water three times to keep a neutral $\mathrm{pH}$. Between each rinse, the sediment was centrifuged for 30 minutes at 3000 RPM until the supernatant was visually clear. For grain size measurement, a dilute solution of $\mathrm{Na}\left(\mathrm{PO}_{3}\right)_{6}$ was used as disperse medium to prevent flocculation of clay particles. Each sample was measured three times and the results were averaged.

As grain size distribution shows multi-modal pattern, the de-convolution into log-normal distribution for the original bulk grain size distribution was performed to distinguish typical grain size populations, 
which enable us to examine the variability of the modal grain size and the contribution of each subpopulation. We assume that bulk grain size distribution is expressed as a combination of several log-normal distributions, where each log-normal distribution could represents typical grain size subpopulation attributable to its own transport process such as suspension, saltation, and bottom traction. The estimation of the number of grain size subpopulation, their modal grain size, half height width, and contribution were conducted and automatically show the output using a multi-peak fit routine provided in IGOR Pro software. This method not only provides accurate sub-populations, but reflects the variability of the modal grain size.

\subsection{Electron spin resonance signal intensity, content, and crystallinity index of quartz grains}

Fifty samples from core MD06-3040 covering the last 10000 years were selected for provenance discrimination of quartz grains. We also prepared samples from a flooding layer and background sediments of core YD09-01 taken from the subaqueous Yangtze Delta (Fig. 1) for comparison with the Yangtze-derived materials. Core YD09-01, representing a 600-year flood history in the Yangtze River drainage, has been described in detail by Wang et al. (2011). The $\mathrm{Zr} / \mathrm{Rb}$ ratio was chosen as a proxy for Yangtze River floods as $\mathrm{Zr}$ deposits primarily in the coarse-grained minerals, and $\mathrm{Rb}$ tends to be found in the fine-grained minerals. The discharge of the Yangtze River increases while flooding occurs, allowing transport of more coarse-grained minerals into the ECS. Therefore, higher the $\mathrm{Zr} / \mathrm{Rb}$ peaks, the greater number of coarse particles transported and deposited. Samples with high $\mathrm{Zr} / \mathrm{Rb}$ peaks and medium $\mathrm{Zr} / \mathrm{Rb}$ representing Yangtze River flood layers and background sediments in Yangtze Delta respectively were chosen. Other potential source materials such as Yellow, Qiantang, $\mathrm{Ou}$, and Min Rivers were examined. The pretreatment was necessary for electron spin resonance (ESR) signal intensity measurement in order to isolate the detrital components such as carbonate from samples with 20 vol \% acetic acid solutions, manganese-iron oxide with $0.3 \mathrm{~mol} / \mathrm{L}$ sodium citrate and $1.0 \mathrm{~mol} / \mathrm{L}$ sodium bicarbonate, and organic matter with $10 \%$ hydrogen peroxide solution. After these pretreatment, samples were separated into 4-16 $\mu \mathrm{m}$ and 16-63 $\mu \mathrm{m}$ fractions using the syringe and pipette methods. ESR, content (QC), and crystallinity index (CI) were determined for these two grain size fractions.

The ESR signal intensity of the E' 1 center in quartz, an unpaired electron in a single silicon $\mathrm{sp}^{3}$ orbit oriented along a bond direction into an oxygen vacancy (Feigl et al., 1974), was used to estimate the 
relative number of oxygen vacancies in quartz. Oxygen vacancies in quartz have been formed by natural radiation, and are known to associate with the age of the host (Toyoda, 2000; Nagashima et al., 2007), which meant that high values of ESR signal intensity of the E'1 center in quartz correlate with old hosts. Firstly, pretreated samples were irradiated with $\gamma$-radiation (total dose of $2.5 \mathrm{kGy}$ ) using a ${ }^{60} \mathrm{Co}$ source at the Inter-University Laboratory for the Joint Use of Japan Atomic Energy Agency Facilities. Consequently, pretreated samples were heated at $300{ }^{\circ} \mathrm{C}$ for 15 minutes to convert the oxygen vacancies to E'1 centers (Toyoda and Ikeya, 1991). ESR signal intensity measurements were conducted at room temperature with an X-band ESR spectrometer JEOL JES-FA100 at University of Tokyo under $0.01 \mathrm{~mW}$ of microwave power, and $0.1 \mathrm{mT}$ magnetic field modulation $(100 \mathrm{kHz}), 5 \mathrm{mT}$ scan range, two minutes scan time, and 0.03 seconds time constant. Intensity of the E'1 centers was normalized to the quartz content of each sample to estimate the ESR signal intensity of pure quartz. The ESR signal intensity of quartz is expressed in spin units: one spin unit is equivalent to $1.3 \times 10^{15} \mathrm{spins} / \mathrm{g}$ (Toyoda and Naruse, 2002). The reproducibility of ESR signal intensity was \pm 1.5 spin units.

The quartz contents (QC) were determined by the internal standard method (Klug and Alexander, 1974), with silicon (Wako Co., Ltd.) as the internal standard, using a PANalytical X'Pert PRO X-ray diffractometer (XRD) at University of Tokyo. An incident beam was generated by a CuK tube at voltage of $45 \mathrm{kV}$ and current of $40 \mathrm{~mA}$ and used with divergence slit of $1^{\circ}$ width. The diffracted beam was set with anti-scatter slit of $5.5 \mathrm{~mm}$ width and soller slit with 0.04 radian opening, filtered by a Ni filter of $0.02 \mathrm{~mm}$ thick, and detected by a real-time multiple strip (RTMS) detector with scanning mode. The scanned interval was $3^{\circ}$ to $80^{\circ} 2 \theta$ with sampling steps of $0.0167^{\circ} 2 \theta$, at four minutes per each sample. Peak areas of quartz at $20.8^{\circ}$ and silicon standard at $28.5^{\circ}$ were measured from the XRD profile, and the area ratio between quartz and silicon was translated to weight percent of quartz content using a pre-determined calibration equation. Reproducibility of the quartz content was $\pm 3 \%$.

The crystallinity index (CI) of quartz was originally defined by Murata and Norman (1976) on the basis of the degree of resolution of the $d(212)$ reflection of quartz at $1.3820 \AA$ on the XRD profile, which could reflects physical conditions during quartz formation and is typically highest in quartz that has formed under high temperatures and or has crystallized slowly. In this study, the measurement followed the approach in Nagashima et al. (2007), where the scaling factor, which was 
introduced to adjust the CI of automorphic quartz to 10, was set at 1.246, using clear automorphic quartz of an industrial standard sample (20-28 mesh granular quartz; Wako Co., Ltd.) as the reference sample. The measurement was conducted with the same equipment above with divergence slit of $1^{\circ}$ for incident beam. The scanned interval was 66 to $69^{\circ} 2 \theta$ with sampling step of $0.0042^{\circ} 2 \theta$, which took 5 minutes per one sample. Reproducibility of the CI for five repeated XRD measurements was \pm 0.3 .

\section{Results}

\section{1. $A M S^{14} \mathrm{C}$ dating and sedimentation rates}

The sedimentation rate of core MD06-3040 ranged from 1 to $4 \mathrm{~mm} / \mathrm{y}$, and approximately $2 \mathrm{~mm} / \mathrm{y}$ on average. Assuming constant sedimentation rates between age control horizons by $\mathrm{AMS}^{14} \mathrm{C}$ date (Table 1), the ages of lithostratigraphic unit boundaries were $\sim 9600$ cal BP between Unit 1 and 2 and 7500 cal BP between Unit 2 and 3. Although the age control was poor at the bottom of the core MD06-3040, the sedimentation rate of Unit 1 and 2 was lower than Unit 3. Within Unit 3, sedimentation rate was moderate in lower part up to $5500 \mathrm{cal} \mathrm{BP}$, higher from 5500 to $3300 \mathrm{cal} \mathrm{BP}$, lower from 3300 to 1400 cal BP, increased again since $1400 \mathrm{cal} \mathrm{BP}$, and highest for the last $300 \mathrm{cal} \mathrm{BP}$. The sedimentation rate rose abruptly since 1200-1400 cal BP at 3.00-3.33 m depth, correlated with the disconformities between $3.00-3.18 \mathrm{~m}$ and 3.20-3.33 $\mathrm{m}$ in the lithological description.

\subsection{Grain-size distribution}

Grain size distribution of core MD06-3040 sediment shows a common grain size mode at 4-8 $\mu$, with accompanying shoulders at 0.8-4 $\mu \mathrm{m}$ and 16-22 $\mu \mathrm{m}$ (Fig. 4). The 16-22 $\mu \mathrm{m}$ shoulders were dominant and formed another mode, together with the occurrence of sand (>100 $\mu \mathrm{m})$ mode. Based on the de-convolution of the grain size distributions into log-normal distributions, four grain size subpopulations, clay, fine silt, coarse silt, and sand were identified.

The modal grain size of each subpopulation was variable at 1-4 $\mu \mathrm{m}$ for clay, 4-8 $\mu \mathrm{m}$ for fine silt, and 16-98 $\mu \mathrm{m}$ for coarse silt subpopulations. For instance, the sample at depth of $1 \mathrm{~m}$ (Fig. 4a) consists of three subpopulations with modal grain sizes of $0.89 \mu \mathrm{m}, 6 \mu \mathrm{m}$, and $16 \mu \mathrm{m}$. The sample at a depth of 3 $\mathrm{m}$ exhibited a combination of three subpopulations with modal grain sizes of $0.94 \mu \mathrm{m}, 7.8 \mu \mathrm{m}$, and 98 $\mu \mathrm{m}$ (Fig. 4b). Compared with the sample at depth of $1 \mathrm{~m}$ (Fig. 4a), the modal grain size of clay of $\sim 1$ 
$\mu \mathrm{m}$ in the sample at $3 \mathrm{~m}$ depth (Fig. 4b) was similar, but the modal grain size of the fine silt subpopulation shifted from $6 \mu \mathrm{m}$ to $7.8 \mu \mathrm{m}$. The lack of coarse silt and the occurrence of the sand subpopulation between 2.57 and $3.3 \mathrm{~m}$ is characteristic in this interval (upper part of Unit 3). Occurrence of larger modal grain size in the coarse silt subpopulation was observed between 12.62 and $15.86 \mathrm{~m}$ in the lower part of Unit 3.

The sample at depth of $16.6 \mathrm{~m}$ in Unit 2 included four subpopulations with modal grain sizes of $1 \mu \mathrm{m}$, $5 \mu \mathrm{m}, 21 \mu \mathrm{m}$, and $105 \mu \mathrm{m}$, respectively (Fig. 4c). The bottom sediments are characterized by a parallel increase in modal grain size and higher concentrations of coarse silt and sand subpopulations, compared with the upper part of the sediment. For example, the sample at depth of $19 \mathrm{~m}$ in Unit 1 shows four subpopulations with modal grain sizes of $2.4 \mu \mathrm{m}, 12.8 \mu \mathrm{m}, 32 \mu \mathrm{m}$, and $130 \mu \mathrm{m}$ (Fig. 4d). The modal grain size of clay in Unit 2 was $2.4 \mu \mathrm{m}$, compared to $1 \mu \mathrm{m}$ in Unit 1 and 3. The modal fine silt grain size in Unit 2 also rose from 5-6 $\mu \mathrm{m}$ to $12.8 \mu \mathrm{m}$, from $21 \mu \mathrm{m}$ to $32 \mu \mathrm{m}$ in coarse silt, and from $105 \mu \mathrm{m}$ to $130 \mu \mathrm{m}$ in sand. Unit 1 and 2 are markedly different from Unit 3.

\subsection{ESR Signal Intensity and Crystallinity Index (CI) of Quartz}

The ESR signal intensity of quartz in the 4-16 $\mu \mathrm{m}$ fractions of MD06-3040 core samples ranged between 3.78 and 23.98 (average, 10.48), whereas those in the 16-63 $\mu \mathrm{m}$ fraction mostly ranged between 4.10 and 13.36 (average 7.84). ESR signal intensity higher than 15 are only found in Unit 3 for the 4-16 $\mu \mathrm{m}$ fraction. The comparison of the ESR signal intensity in the 4-16 $\mu \mathrm{m}$ fraction with the change of each grain size subpopulations revealed that ESR signal intensity in 4-16 $\mu \mathrm{m}$ fractions suddenly increase while shifting of clay, fine silt and coarse silt subpopulations. For instance, these samples at $3.73 \mathrm{~m}$ ( 1880 a), $6.61 \mathrm{~m}$ ( 3694 a), $8.25 \mathrm{~m} \mathrm{( \sim 4230} \mathrm{a),11.33} \mathrm{m} \mathrm{(} \mathrm{5289} \mathrm{a),} 13.81 \mathrm{~m}$ ( 6667 a) show higher ESR signal intensity in 4-16 $\mu \mathrm{m}$ fraction, which could be associated with the variations in grain size subpopulations where fine silt population and coarse silt population shifted (Fig.5). However, even with the variety of subpopulations and modal grain size change at the bottom of core, the value of ESR signal intensity in the 16-63 $\mu \mathrm{m}$ fraction was not so variable through the whole core as was the 4-16 $\mu \mathrm{m}$ fraction. The CI value of quartz in the 4-16 $\mu \mathrm{m}$ fraction varied within a narrow range between 7.66 and 8.73 (average, 8.31), whereas those in the 16-63 $\mu \mathrm{m}$ fraction range between 7.02 and 8.63 (average, 8.06) and CI values lower than 7.5 are only found after $5000 \mathrm{BP}$.

Fig. 6 shows the relationship between the ESR signal intensity and the CI of quartz in the 4-16 $\mu \mathrm{m}$ 
and 16-63 $\mu \mathrm{m}$ fractions, respectively. Data for the flooding and background sediments of core YD09-01 taken from subaqueous Yangtze Delta and local river sediments were also plotted in order to visualize the difference in source areas of the quartz on the inner shelf of ECS obtained from different sedimentological settings and size dependency of quartz provenance. Most of core MD06-3040 sediment samples in the 4-16 $\mu \mathrm{m}$ fraction were plotted near an area marked by background Yangtze-derived sediments (Fig.6a). However, several samples with higher ESR signal intensity, such as at $3.73 \mathrm{~m}$ ( 1880 a), $6.61 \mathrm{~m} \mathrm{(} \mathrm{3694} \mathrm{a),} 8.25 \mathrm{~m}(\sim 4230 \mathrm{a}), 11.33 \mathrm{~m} \mathrm{(} \mathrm{5289} \mathrm{a),} \mathrm{and}$ $13.81 \mathrm{~m} \mathrm{(} \mathrm{6667} \mathrm{a),} \mathrm{were} \mathrm{close} \mathrm{to} \mathrm{flood} \mathrm{layer} \mathrm{sediment} \mathrm{samples} \mathrm{of} \mathrm{YD09-01.} \mathrm{Core} \mathrm{MD06-3040}$ sediment samples at $14.97 \mathrm{~m}$ ( 7170 a), $16.65 \mathrm{~m}$ ( 8143 a), $17.65 \mathrm{~m}$ ( 9026 a), $17.73 \mathrm{~m}$ ( 9097 a), and $18.33 \mathrm{~m}$ ( 9627 a) show medium ESR signal intensity and low CI. Most samples in the 16-63 $\mu \mathrm{m}$ fraction (Fig. 6b) plotted within a narrow range which overlapped an area marked by both flooding and background sediments in the Yangtze Delta. The samples at $0.41 \mathrm{~m}(\sim 73 \mathrm{a}), 0.85 \mathrm{~m}$ ( 152 a), $3.53 \mathrm{~m}(\sim 1693 \mathrm{a})$, and $4.01 \mathrm{~m}$ ( 2143 a), however, show relatively low and medium ESR and low CI values.

\section{Discussion}

\subsection{Development of the mud belt and alongshore transport of the Yangtze-derived sediment during} the mid-late Holocene

The postglacial sea-level rise provided a large accommodation for river-derived sediment, which is believed to give a significant influence on the inner shelf sedimentation in the ECS (Hu et al., 1984; Christie Blick and Driscoll, 1995; Huh et al., 1999; Chen et al., 2000; Berne, et al., 2002). The sedimentation and sonic profile of MD06-3040 show a typical sedimentary sequence known in this area (Liu et al., 2000; Liu et al., 2007).

A prominent reflector at $-67 \mathrm{~m}$ (Fig. 3f) might be interpreted to correspond to TS formed during MWP-IA, widely recognized at 70 to $90 \mathrm{~m}$ of depth below sea level (Liu et al., 2007) although core MD06-3040 could not penetrate this horizon. Sandy silt in Unit 1 and 2 corresponding to a transparent sonic character at $65 \mathrm{~m}$ below sea level might represent a transgressive systems tract (TST) formed before sea level reached its highstand. The AMS ${ }^{14} \mathrm{C}$ age of $10325 \mathrm{BP}$ of Unit 1 suggests this unit was deposited under a water depth of $27 \mathrm{~m}$, considering the sea level during this period (Liu, et al., 2004), which made this unit more sandy than Unit 2. The fining-upward succession from Unit 1 to 2 could be 
interpreted as a transition from the nearshore shelf with tidal influence to the nearshore subtidal environment in response to the postglacial sea-level rise. This TST in the ECS was generally thin, less than $2 \mathrm{~m}$, which suggested sea level rose quickly and insufficient sediments were contributed (or at least accumulated) on the inner shelf of ECS during the last transgression (Liu et al., 2007). Such a starved sediment supply during TST formation is also supported by a relatively lower sedimentation rate of Unit 1 and 2. However the total thickness of Unit 1 and 2 of core MD06-3040 was more than 3 $\mathrm{m}$. This is probably because shallower facies represented by Unit 1 have not been recognized in the previous studies whereas the facies observed in Unit 2 has been widely recognized as TST. The top of Unit 2 is bounded by clear lithological transition boundary at $15.85 \mathrm{~m}$, the age of which was estimated as $7500 \mathrm{BP}$. This boundary between Unit 2 and 3 might be interpreted to represent MFS. Accordingly, the mud belt was continually deposited on the inner shelf of the East China Sea since the middle Holocene high stand at 7500-7000 BP (Li et al., 2002; Liu et al., 2004, 2010).

The sediment of Unit 3 was believed to correspond to a huge mud belt deposited as high stand system tract (HST) based on silty clay to clayey silt facies and depositional age younger than $7500 \mathrm{BP}$. Those sediments deposited below $12.62 \mathrm{~m}(\sim 6000 \mathrm{BP})$ in the lower Unit 3 exhibited a (quasi-) bimodal grain size distribution identical to typical sediments in the mud belt margin, which could be formed as a combination of the fine and coarse sediments under relatively higher energy environments (Liu et al., 2006). This grain size distribution pattern also suggested that besides the predominant Yangtze sediment, there might be some local inputs such as the Qiantang or Ou Rivers. This interpretation might be supported by the higher ESR signal intensity of the 4-16 $\mu \mathrm{m}$ fraction between 12.62 and 15.85 m, similar to those of the Qintang and Ou Rivers (Fig. 6).

The sediments of Unit 3 between the top and $12.62 \mathrm{~m}$ show relatively consistent grain size distribution dominated by fine silt except for a sandy horizon between 3.1 and $3.2 \mathrm{~m}$. Although the sediment consists of three coexisting subpopulations (clay, fine silt, and coarse silt) with variable modal grain size, the fine silt dominated single-modal grain-size distribution is identical to the fine-grained Yangtze-derived sediment, the main constituent of mud belt sediment. The higher sedimentation rate above $12.62 \mathrm{~m}$ than the below in Unit 2 also suggests the beginning of significant contributions from fine-grained Yangtze-derived sediments after 6000 BP. The abrupt change of sand population at 3.1-3.3 $\mathrm{m}$ in Unit 3 that is also observed as a relatively strong reflector directly below the sea floor (Fig. 3f) could be associated with the accelerated progradation rate, reflecting an increase in sediment 
production in the Yangtze drainage (Liu et al., 2007).

Variability in lithology of MD06-3040 has been largely affected by the various sedimentary environments since the last deglaciation, which was primarily controlled by sea level change. While transgression was responsible for formation of Unit 1 and 2, the contribution of the Yangtze sediment discharge played a significant role in the sedimentation of Unit 3 under a relatively stable sea level since 7500 BP. Especially, the Unit 3 sediment above $12.62 \mathrm{~m}$ might be suitable to examine the nature of the Yangtze-derived sediment, suggested by its consistent fine silt.

\subsection{Variability in the Yangtze River discharge associated with EASM precipitation}

Since 6000 BP, the variations of grain size have correlated well with fluctuation of provenance proxy ESR signal intensity in Unit 3. The high ESR signal intensity in the 4-16 $\mu \mathrm{m}$ fraction corresponded to increasing modal grain size of the fine silt fraction (Fig. 5b and 5c). Larger grain size might be explained by coarsening of suspended materials supplied by the Yangtze River due to frequent flooding caused by heavier precipitation and stronger EASM. This view is also supported by the Yangtze Delta core YD09-01 sediments, where high ESR signal intensities are observed in flooding layers, suggesting stronger EASM. Therefore, we assume that the modal grain size of the fine silt fraction could be an EASM indicator (Fig. 7a).

On the other hand, suspended material, temperature, and salinity surveys conducted in the northwestern ECS show that near-bottom concentrations of suspended matter are much higher during the winter than the summer, due to winter storms and the well-mixed water column (Hu et al., 1984). Consequently, the increase in grain size within this region has been interpreted as a strengthening of CCC, which was driven by the EAWM (Milliman et al., 1985, 1989; Yang et al., 1992; Guo et al., 2002, 2003; Xiao, 2004, 2006). At the core MD06-3040 site, higher ESR signal intensity in the 16-63 $\mu \mathrm{m}$ fraction can be explained by an enhanced influence from local rivers as well as the change in provenance of the Yangtze-derived sediment (Fig. 6b). Therefore, the input from local rivers such as the Qintang and Ou Rivers might be another possibility explaining high ESR signal intensity, which is associated with larger grain size in MD06-3040 sediments. Potential influences on the grain size of sediment from variability of CCC and local rivers input could appear in the coarser grain size range. The contribution of coarse silt fraction relative to fine silt fraction was examined (Fig. 7b) and compared with the modal grain size of fine silt fraction (Fig. 7a) in order to differentiate thhe 
influence of CCC or local input on the grain size variability influenced by EASM.

The general resemblance of the temporal profiles of modal grain size of fine silt fraction (Fig. 7a) and coarse silt / fine silt ratio (Fig. 7b) suggest a prevailing control of the Yangtze River discharge on grain size parameters. Significant variability in the modal grain size of fine silt fraction shows notable decreases at $6000 \mathrm{BP}, 5300 \mathrm{BP}, 4500 \mathrm{BP}, 3700-3300 \mathrm{BP}, 2200 \mathrm{BP}, 1400-1300 \mathrm{BP}$, and 800-600 BP, most of which are matched well with minima of coarse silt / fine silt ratio (Fig. 7b). However, the minimum event at 3700-3300 BP recognized in modal grain size of the fine silt fraction (Fig. 7a) has not been found in the coarse silt / fine silt ratio (Fig. 7b). In contrast, the significant minimum at $2500 \mathrm{BP}$ observed in the coarse silt / fine silt ratio does not show a corresponding minimum in the modal grain size of fine silt. We assume that the resuspension and redeposition of sediment particles might be responsible for the dissimilarity between these grain size parameters. Additional supply of coarser materials by stronger water column mixing during the high sedimentation rate period (3500-5000 BP Fig. 5a) might have increased the coarse silt / fine silt ratio. Other oceanic process such as coastal currents also could dilute the grain size signals controlled by the EASM. In spite of some potential influence on grain size records from coastal current and local input, consistent minima for both grain size parameters (Fig. 7a and 7b) at 6000 BP, 5300 BP, 4500 BP, 2200 BP, 1400-1300 BP, and 800-600 BP might represent strong evidence of lower discharge (drought) events of the Yangtze drainage.

Jiang et al. (2005) summarized historical natural calamity records and described frequent drought periods in Yangtze Delta from 800 AD to 900 AD, 1000 AD to 1200 AD, and after 1450 AD, where the recurrence interval was 100-200 y and the duration of each frequent drought event was several decades to a hundred years. They also indicate that frequent droughts tended to occur just after frequent flooding. The periods from $1550 \mathrm{AD}$ to $1850 \mathrm{AD}$ and from $1000 \mathrm{AD}$ to $1200 \mathrm{AD}$ in the Yangtze Delta region have been also recognized as frequent flooding / drought periods (Zhang et al., 2002). Another historical data set including frequencies of floods and droughts suggested drought periods during 6200-5900 BP and 4000-3900 BP within the middle and lower reaches of the Yangtze (Wang and Huang, 2006). Most of the lower discharge (drought) events found in our core MD06-3040 could be correlated with these historical drought periods on millennial scales (Fig. 7a and 7b). Typical recurrence interval of 100-1000 y and duration of $\sim 100 \mathrm{y}$ for frequent drought periods also seem to be consistent with our grain size record, which suggests that the precipitation in 
the Yangtze drainage could be a dominant control on the discharge and the grain size characteristics of suspended materials.

Reconstructed ECS $\delta^{18} \mathrm{O}_{\mathrm{w}}$ derived from paired measurement of $\mathrm{Mg} / \mathrm{Ca}$ and $\delta^{18} \mathrm{O}$ of foraminifera calcite has been applied as an indirect indicator of the past salinity in the northern ECS core KY07-04-01 (Kubota et al., 2010, 2014). They recognized high salinity events at 6000 BP, 5100 BP, 4300 BP, 3500 BP, 2100 BP, and 800-600 BP (Fig. 7c), which corresponded well with minima of grain size parameters of core MD06-3040 except for a grain size minimum at 1400-1300 BP (Fig. 7a and $7 b$ ). This correlation signifies strong ties between northern ECS and inner shelf of ECS regions, where cores are strongly influenced by Yangtze River discharge. An inconsistency at 1400-1300 BP might be due to lesser sampling resolution in KY07-04-01, or an influence from human disturbance during the last $2000 \mathrm{BP}$.

The reconstruction of Holocene rainfall derived by comparing high-resolution stalagmite $\delta^{18} \mathrm{O}$ records (calibrated $\Delta \delta^{18} \mathrm{O}_{\mathrm{sp}}$ record) also provides a quantitative history of rainfall in southwest China (Hu et al., 2008). Significant multi-centennial/millennial variability also occurred, with notable dry periods at 6000 BP, 4800-4100 BP, 3700-3100 BP, 1400-1000 BP, and during the Little Ice Age (Fig. 7d). Hu et al. (2008) compared the stalagmite $\delta^{18} \mathrm{O}$ record from Heshang Cave during the Holocene with the record from Dongge Cave, $600 \mathrm{~km}$ to the southwest of Heshang Cave, directly upstream along the same moisture transport pathway during the summer monsoon season. $\Delta \delta^{18} \mathrm{O}_{\mathrm{sp}}$ does not show agreement, with gradual decrease in precipitation and summer insolation since the middle Holocene (Wang et al., 2001, 2005; Kubota, et al., 2014). Variation in grain size proxies of core MD06-3040 could be correlated with $\delta^{18} \mathrm{O}_{\mathrm{w}}$ of the northern ECS core KY07-04-01 (Kubota et al. 2010) and the stalagmite $\Delta \delta^{18} \mathrm{O}_{\mathrm{sp}}$ record (Hu et al., 2008) within age uncertainties, demonstrating similar patterns of temporal variations characterized by millennial-scale EASM precipitation changes (Fig.7). These common characteristic response patterns indicate that EASM precipitation in South China should be a dominant control on the Yangtze River discharge, and accordingly influence deposition of Yangtze-derived sediment on the inner shelf of ECS and ECS salinity. The common event observed in grain size parameters of core MD06-3040 and $\delta^{18} \mathrm{O}_{\mathrm{w}}$ of northern ECS core KY07-04-01 (Fig. 7a, b, and c) at 5300 BP is not observed in the reconstructed precipitation from the stalagmite $\Delta \delta^{18} \mathrm{O}_{\text {sp }}$ record (Fig. 7d), which might be due to spatial heterogeneity of the precipitation pattern caused by the shift of the EASM front within the Yangtze River drainage. The quasi-cyclic 
nature in core MD06-3040 representing drought events with recurrence interval of 700-1000 y is similar to stalagmite $\delta^{18} \mathrm{O}$ variability in southeastern China, although the cause(s) of its variability is not well understood (Ding et al., 2009, Wan et al., 2011, Liu et al., 2014).

Sand occurrence between 3.1-3.2 m ( 1400 BP) followed by an increase in sedimentation rate was another prominent feature in core MD06-3040, which might reflect an increase in progradation rate on the inner shelf of ECS due to human impact on the Yangtze drainage. This is exactly the same as Yangtze delta core YD09-01, with high sedimentation rate since 1500 BP (Wang et al., 2011). Human disturbance within the Yangtze River drainage potentially obscures the climate signals through sediment mobility by land use change, such as deforestation and settlement. A historical maximum in human activity in the lower Yangtze region was reached during 1200-1000 BP when several ancient relics were found and agricultural activities intensified (Stanley et al., 1994, 1996; Chen et al., 2001, 2012). Evidence for human impact through intensive cultivation and burning is particularly clear since 2000 BP, which could impact palaeoclimate records. We assume human activity could explain the frequent changes recorded in the modal size of fine silt fraction and the coarse silt / fine silt ratio and of core MD06-3040 (Fig. 7a and 7b) during the last 2000 years. The correlations among the precipitation location, the Yangtze delta progradation, the shift of the Yangtze River channel, coastal current intensity, transportation of Yangtze-derived sediments, and recent land use change by human activity must be further addressed in future study.

\section{Conclusions}

The variations of grain-size give strong clues to changes of the Yangtze River discharge and transport patterns of terrigenous sediments. Significant variability occurred in the core MD06-3040 with notable decrease in East Asian Summer Monsoon precipitation (drought events) at 6000 BP, 5300 BP, $4500 \mathrm{BP}, 3700-3300 \mathrm{BP}, 2200 \mathrm{BP}, 1400-1300 \mathrm{BP}$, and 800-600 BP, which coincided with $\delta^{18} \mathrm{O}_{\mathrm{w}}$ record in the northern ECS and the stalagmite $\Delta \delta^{18} \mathrm{O}_{\mathrm{sp}}$ records from southern China during the Holocene. The shifts of grain-size are also attributable to the provenance change due to flood events within the Yangtze River drainage. We hypothesize that the dominant impact of Yangtze River discharge association with EASM precipitation have been recognized in core MD06-3040, although the grain size signal tends to be obscured by sediment reworking and redeposition by coastal current and local input, heterogeneity of precipitation area, and human activities. In order to resolve the 
correlation among the precipitation localization, the Yangtze delta progradation, the shift of the channels, coastal current intensity, transportation of Yangtze-derived sediments, and recent land use changed by human activity, a detailed comparison between our mud belt core and more proximal Yangtze delta sediment core would be necessary.

\section{Acknowledgements}

The authors sincerely thank all crews of MD155-Marco Polo II-IMAGES XIV cruise on board for providing cores MD06-3039 and MD06-3040. We also thank researchers and staff at Tongji University, Institute of Geochemistry in Guangzhou, Chinese Academy of Sciences (CAS) and Peking University for laboratory assistance. We also thank anonymous reviewers for constructive comments greatly improving this manuscript. This study was jointly supported by Grant for Scientific Research from the Japan Society for Promotion of Science Grant No. 23221002 and the CAS Strategic Priority Research Program Grant No. XDA05130502.

\section{References}

Beardsley, R.C., Limeburner, R., Yu, H., Cannon, G.A., 1985. Discharge of the Changjiang (Yangtze River) into the East China Sea. Continental Shelf Research 4 (1-2), 57-76.

Becker, S., Hartmann, H., Zhang, Q., Wu, Y., Jiang, T., 2008. Cyclicity analysis of precipitation regimes in the Yangtze River basin, China. International Journal of Climatology 28, 579-588.

Berne, S., Vagner, P., Guichard, F., Lericolais, G., Liu, Z., Trentesaux, A., Yin, P., Yi, H.I., 2002. Pleistocene forced regressions and tidal sand ridges in the East China Sea. Marine Geology 188 (3-4), 293-315.

Chang, W. King G. 1999. Centennial climate changes and their global associations in the Yangtze River (Chang Jiang) Delta, China and subtropical Asia. Climate Research 2, 95-103.

Chang, P., Isobe, A., 2003. A numerical study on the Changjiang diluted water in the Yellow and East China Seas. Journal of Geophysical Research 108: doi: 10.1029/2002JC001749

Chen, Z.Y., Zhou, C.Z., Yang, W.D., Wu, Z.G., 1986. Submarine topography and sediments off modern Yangtze River. Donghai Marine Science 4 (4), 28-37 (in Chinese, with English Summary).

Chen, Z.Y., Stanley, D.J., 1993. Yangtze delta, eastern China: Late Quaternary subsidence and deformation. Marine Geology 112 (1-4), 13-21.

Chen, Z.Y., Chen, Z.L., Zhang, W., 1997. Quaternary stratigraphy and trace-element indices of the Yangtze Delta, Eastern China, with special reference to marine transgressions. Quaternary Research 47 (2), 181-191.

Chen, Z.Y, Song, B., Wang, Z., Cai, Y., 2000. Late Quaternary evolution of the sub-aqueous Yangtze Delta, China: sedimentation, stratigraphy, palynology, and deformation. Marine Geology 162 (2-4), 423-441.

Chen, Z.Y, Li, J., Shen, H., Wang, Z.H., 2001. Yangtze River of China: historical analysis of discharge variability and sediment flux. Geomorphology 41 (2-3), 77-91.

Chen, Z.Y, Saito, Y., Hori, K., Zhao, Y., Kitamura, A., 2003. Early Holocene mud-ridge formation in the Yangtze offshore, China: a tidal-controlled estuarine pattern and sea-level implications. Marine Geology, 198, 245-257.

Chen, Z.Y., Saito, Y., Kanai, Y., Wei, T., Li, L., Yao, H., Wang, Z., 2004. Low concentration of heavy 
metals in the Yangtze estuarine sediments, China: a diluting setting. Estuarine, Coastal and Shelf Science 60 (1), 91-100.

Christie Blick, N., Driscoll, N. W., 1995. Sequence stratigraphy: Annual Review of Earth and Planetary Sciences, 23, p. 451-478

Dagg, M., Benner, R., Lohrenz, S., Lawrence, D., 2004. Transformation of dissolved and particulate materials on continental shelves influenced by large rivers: plume processes. Continental Shelf Research 24 (7-8), 833-858.

Demaster, D.J., McKee, B.A., Nittrouer, C.A., Qian, J.C., Cheng, G.D., 1985. Rates of sediment accumulation and particle reworking based on radiochemical measurements from continental-shelf deposits in the East China Sea. Continental Shelf Research 4 (1-2), 143-158.

Deng, B., Zhang J., and Wu Y., 2006. Recent sediment accumulation and carbon burial in the East China Sea, Global Biogeochemical Cycles, 20, GB3014.

Dong L.X., Guan W.B., Chen Q., Li X.H., Liu X.H., Zeng X.M., 2011. Sediment transport in the Yellow Sea and East China Sea. Estuarine, Coastal and Shelf Science 93,248-258.

Feigl, F. J., W. B. Fowler, and K. L. Yip, 1974. Oxygen vacancy model for the E1 center in $\mathrm{SiO}_{2}$, Solid State Communications, 14, 225-229.

Hori, K., Saito Y., Zhao Q.H., Cheng X.R., Wang, P.X. Sato, Y. Li, C.X., 2001. Sedimentary facies and Holocene progradation rates of the Changjiang (Yangtze) Delta, China. Geomorphology 41, 233-248.

Hori, K., Saito, Y., Zhao, Q.H, Wang, P.X, 2002. Architecture and evolution of the tide-dominated Changjiang (Yangtze) River delta, China. Sedimentary Geology 146 (3-4), 249-264.

Hu, C.Y., Henderson, G.M., Huang, J.H., Xie, S.C., Sun, Y., Johnson K.R., 2008. Quantification of Holocene Asian monsoon rainfall from spatially separated cave records. Earth and Planetary Science Letters 266, 221-232.

Hu, D.X., 1984. Upwelling and sedimentation dynamics: 1. the role of upwelling in sedimentation in the Huanghai Sea and East China Sea: a description of general features. Chinese Journal of Oceanologia and Limnologia 2 (1), 12-19 (in Chinese, with English Summary).

Hu, D.X., Yang, Z.S., 2001. Key Processes of the East China Sea Flux. China Ocean Press, Beijing. 204 pp. (in Chinese, with English Summary).

Hughen, K. A., Baillie, M.G.L., Bard, E., Beck, J. W., Bertrand, C. J. H., Blackwell, P. G., Buck, C. E., Burr, G. S., Cutler, K.B., Damon, P.E., Edwards, R.L., Fairbanks, R.G., Friedrich, M.,Guilderson, T.P., Kromer, B., McCormac, G.,Manning, S.,Ramsey, C.B.,Reimer, P.J.,Reimer, R.W.,Remmele, S., Southon, J.R.,Stuiver,M., Talamo,S.,Taylor, F.W., vander Plicht, J., Weyhenmeyer, C.E., 2004. Marine04: marine radiocarbon age calibration, 26-0 ka BP. Radiocarbon 46, 1059-1086.

Huh, C.A., Su, C.C., 1999. Sedimentation dynamics in the East China Sea elucidated from ${ }^{210} \mathrm{~Pb}$, ${ }^{137} \mathrm{Cs}$ and ${ }^{239,240} \mathrm{Pu}$. Marine Geology 160 (1-2), 183-196.

Klug, H. P., Alexander, L.E., 1974. X-Ray Diffraction Procedure: For Polycrystalline and Amorphous Materials, 2nd ed., p. 966.

Kubota, Y., Kimoto, K., Tada, R., Oda, H., Yokoyama, Y., Matsuzaki, H., 2010. Variations of East Asian summer monsoon since the last deglaciation based on $\mathrm{Mg} / \mathrm{Ca}$ and oxygen isotope of planktic foraminifera in the northern East China Sea, Paleoceanography, 25, PA4205, doi:10.1029/2009PA001891.

Kubota, Y., Tada, R., Kimoto, K., 2014. Quantitative reconstruction of East Asian summer monsoon precipitation during the Holocene based on oxygen isotope mass-balance calculation in the East 
China Sea. Climate of the Past Discussions 10, 1447-1492.

Jiang T., Zhang Q., Blender, R. and Fraedrich, K., 2005. Yangtze Delta floods and droughts of the last millennium: Abrupt changes and long term memory. Theoretical and Applied Climatology 82, 131-141.

Jiang, T., Zhang, Q., Zhu, D.M., Wu, Y.J., 2006. Yangtze floods and droughts (China) and teleconnections with ENSO activities (1470-2003). Quaternary International 144, 29-37

Lee, H.J., Chao, S.Y., 2003. A climatological description of circulation in and around the East China Sea. Deep-Sea Research, Part II: Topical Studies in Oceanography 50 (6-7), 1065-1084.

Li, C.X., Ming, Q.B., Sun, H.P., 1986. Holocene strata and transgression of southern Yangtze delta plain. Chinese Science Bulletin 21, 1650-1653.

Li, C.X, Wang, P.X, 1998. Late Quaternary Stratigraphy of the Yangtze Delta. China Science Press, Beijing. 222 pp. (in Chinese).

Li, C.X, Chen, Q., Zhang, J., Yang, S., Fan, D., 2000. Stratigraphy and paleoenvironmental changes in the Yangtze Delta during the Late Quaternary. Journal of Asian Earth Sciences 18 (4), 453-469.

Li, C.X, Deng, B., Zhang, J., Fan, D., 2001. Holocene regression and the tidal radial sand ridge system formation in the Jiangsu coastal zone, east China. Marine Geology 173 (1-4), 97-120.

Li, C.X, Wang, P.X, Sun, H., Zhang, J., Fan, D., Deng, B., 2002. Late Quaternary incised-valley fill of the Yangtze delta (China): its stratigraphic framework and evolution. Sedimentary Geology 152(1-2), 133-158.

Liu, Z.X., Berne, S., Saito, Y., Lericolais, G., Marsset, T., 2000. Quaternary seismic stratigraphy and paleoenvironments on the continental shelf of the East China Sea. Journal of Asian Earth Sciences 18 (4), 441-452.

Liu, J.P., Milliman, J.D., Gao, S., Cheng, P., 2004. Holocene development of the Yellow River's subaqueous delta, North Yellow Sea. Marine Geology 209 (1-4), 45-67.

Liu, J. P., Li, A. C., Xu, K. H., Velozzi, D. M., Yang, Z. S., Milliman, J. D., DeMaster, D. J. 2006. Sedimentary features of the Yangtze River-derived along-shelf clinoform deposit in the East China Sea. Continental Shelf Research 26, 2141-2156.

Liu J.P., Xu K.H., Li A.C., Milliman J.D., Velozzi D.M., Xiao S.B., Yang Z.S. 2007. Flux and fate of Yangtze River sediment delivered to the East China Sea. Geomorphology 85, 208-224.

Liu, Z.F., Colin, C., Li, X.J, Zhao, Y.L, Tuo, S.T, Chen, Z., Siringan, F., Liu, J., Huang C.Y., You C., Huang, K.F, 2010. Clay mineral distribution in surface sediments of the northeastern South China Sea and surrounding fluvial drainage basins: Source and transport. Marine Geology 277, 48-60.

McKee, B., Nittrouer, C., DeMaster, D., 1983. Concepts of sediment deposition and accumulation applied to the continental shelf near the mouth of the Yangtze River. Geology 11 (11), 631-633.

Milliman, J.D, Meade, H.R., 1983. World-wide delivery of sediment to the oceans. Journal of Geology 91 (1), 1-21.

Milliman, J.D, Shen, H., Yang, Z., Meade, H.R., 1985. Transport and deposition of river sediment in the Changjiang estuary and adjacent continental shelf. Continental Shelf Research 4 (1-2), 37-45.

Milliman, J.D, Syvitski, J., 1992. Geomorphic/tectonic control of sediment discharge to the ocean: the importance of small mountainous rivers. Journal of Geology 100 (5), 525-544.

Murata, K., Norman, M. 1976. An index of crystallinity for quartz. American Journal of Science 276, $1120-1130$.

Nagashima, K., Tada, R., Matsui, H., Irino, T., Tani, A., Toyoda, S., 2007. Orbital- and millennial-scale variations in Asian dust transport path to the Japan Sea. Palaeogeography, 
Palaeoclimatology, Palaeoecology. doi:10.1016/j.palaeo.2006.11.027

Nagashima, K., Tada, R., Tani, A., Toyoda, S., Sun, Y., Isozaki, Y., 2007. Contribution of aeolian dust in Japan Sea sediments estimated from ESR signal intensity and crystallinity of quartz. Geochemistry Geophysics Geosystems, 8, Q02Q04.

Qin, Y.S, 1979. A study on sediment and mineral compositions of the sea floor of the East China Sea. Oceanic Selections 2 (2), 130-142.

Qin, Y.S, Zhao, Y.Y., Chen, L.R., Zhao, S.L., 1987. Geology of the East China Sea. China Science Press, Beijing.

Robinson A. R. and NIILER P.P. 1967. The theory of free inertial currents. I. Path and structure. Tellus, 19,269-291.

Saito, Y., Katayama, H., Ikehara, K., Kato, Y., Matsumoto, E., Oguri, K., Oda, M., Yumoto, M., 1998. Transgressive and highstand systems tracts and post-glacial transgression, the East China Sea. Sedimentary Geology 122 (1-4), 217-232.

Saito, Y., Yang, Z.S, Hori, K., 2001. The Huanghe (Yellow River) and Changjiang (Yangtze River) deltas: a review on their characteristics, evolution and sediment discharge during the Holocene. Geomorphology 41 (2-3), 219-231.

Stanley, D., Warne, A., 1994. Worldwide initiation of Holocene marine deltas by deceleration of sea-level rise. Science 265, 228-231.

Stanley, D., Chen, Z., 1996. Neolithic settlement distributions as a function of sea level-controlled topography in the Yangtze delta, China. Geology 24 (12), 1083-1086.

Stuiver, M., Reimer, P., 1993. Extended ${ }^{14} \mathrm{C}$ database and revised CALIB radiocarbon calibration program. Radiocarbon 35, 215-230.

Stuiver, M., Burr, G., Hughen, K. A., Kromer, B., McCormac, G., Van Der Plicht, J., Spurk, M., Reimer, P., Bard, E., Beck, J., 1998. INTCAL98 radiocarbon age calibration, 24,000-0 cal BP. Radiocarbon 40 (3), 1041-1083.

Su, C.C., and Huh, C.A., 2002. ${ }^{210} \mathrm{~Pb},{ }^{137} \mathrm{Cs}$ and ${ }^{239,240} \mathrm{Pu}$ in East China Sea sediments: Sources, pathways and budgets of sediments and radio nuclides. Marine Geology, 183, 163-178.

Syvitski, J., Vorosmarty, C., Kettner, A., Green, P., 2005. Impact of humans on the flux of terrestrial sediment to the global coastal ocean. Science 308 (5720), 376-380.

Tong, Q. C., and Cheng T. W., 1981. Runoff, in Physical Geography of China (in Chinese). Science Press, Beijing.pp. 6-121.

Toyoda, S., Ikeya M, 1991. Thermal stabilities of paramagnetic defect and impurity centers in quartz: Basis for ESR dating of thermal history. Geochemical Journal 25, 437-445.

Toyoda, S., Hattori, M., 2000. Formation and decay of the E1 center and of its precursor. Applied Radiation and Isotopes, 52, 1351-1356.

Toyoda, S., Naruse, T., 2002. Eolian dust from the Asian Deserts to the Japanese islands since the last glacial maximum: The basis for the ESR method. Japan Geomorphology 23(5), 811-820.

Wan N.J., Li H.C., Liu Z.Q., Yang H.Y., Yuan D.X., Chen Y.H., 2011. Spatial variations of monsoonal rain in eastern China: Instrumental, historic and speleothem records. Journal of Asian Earth Sciences 40, 1139-1150.

Wang M. J., Zheng H.B., Xie X., Fan, D.D., Yang, S.Y., Zhao, Q.H., Wang K., 2011. A 600-year flood history in the Yangtze River drainage: Comparison between a subaqueous delta and historical records. Chinese Science Bulletin, 56: 188-195.

Wang S.W., Huang, J.M., 2006. Variability of dryness/wetness during the mid-Holocene. Progress in 
Natural Science, 16(10), 1238-1244 (in Chinese).

Wang, Y.J., Cheng, H., Edwards, R.L., An, Z.S., Wu, J.Y., Shen, C.C., Dorale, J.A., 2001. A high-resolution absolute-dated late Pleistocene monsoon record from Hulu Cave. Science 294, 2345-2348.

Wang, Y.J., Cheng, H., Edwards, R.L., He, Y.Q., Kong, X.G., An, Z.S., Wu, J.Y., Kelly, M.J., Dykoski, C.A., Li, X.D., 2005. The Holocene Asian monsoon: links to solar changes and North Atlantic climate. Science 308, 854-857.

Xiang R., Yang, Z.S., Saito, Y., Guo Z.G., Fan, D.J, Li, Y.H., Xiao, S.B., Shi, X.F., Chen, M.H., 2006. East Asia Winter Monsoon changes inferred from environmentally sensitive grain-size component records during the last 2300 years in mud area southwest off Cheju Island, ECS. Science in China: Series D Earth Sciences 49(6) 604-614.

Xiao, S. B., Li, A.C., Jiang, F.Q., Gang, L.T., Huang, P., Xu, Z.K., 2004. Mud deposit records in the inner shelf of the East China Sea since near 2000 a BP and its climate significance. Chinese Science Bulletin 49 (21), 2233-2238.

Xiao, S.B., Li, A.C., Liu, J.P., Chen, M.H., Xie, Q., Jiang, F.Q., Li, T.G., Xiang, R., Chen, Z., 2006. Coherence between solar activity and the East China Asian winter monsoon variability in the past 8000 years from Yangtze River-derived mud in the East China Sea. Palaeogeography, Palaeoclimatology, Palaeoecology 237, 293-304.

Xiao, S.B., Liu, W.G., Li, A.C., Yang, S.Y., Lai, Z.P., 2010. Pervasive autocorrelation of the chemical index of alteration in sedimentary profiles and its palaeoenvironmental implications. Sedimentology 57, 670-676.

Yan, Q.S., Hong, X.Q., 1987. Holocene transgression on the southern Yangtze plain. Acta Geographica Sinica 9 (6), 744-752 (in Chinese, with English Summary).

Yancheva, G., Nowaczyk, N.R., Mingram, J., Dulski, P., Schettler, G., Negendank, J.W., Liu, J.Q., Sigman, D.M., Peterson, L.C., Haug, G.H. 2007. Influence of the intertropical convergence zone on the East Asian monsoon. Nature 445, doi:10.1038/nature05431.

Yang, H.R., Xie, Z.R., 1984. Sea-level changes along the east coast of China over the last 20000 years. Oceanologia et Limnologia Sinica 15 (1), 1-13 (in Chinese, with English Summary).

Yang, Z.S., Guo, Z.G., Wang, Z.X., 1992. Basic pattern of transport of suspended matter from the Yellow Sea and East China Sea to the eastern deep seas. Acta Oceanologica Sinica 14 (2), 81-90 (in Chinese, with English Summary).

Zhang, J., and Liu, C.L., 2002. Riverine composition and estuarine geochemistry of particulate metals in China-weathering features, anthropogenic and chemical fluxes. Estuarine Coastal Shelf Science, 54, 1051-1070.

Zhang. Q., Zhu C., Cheng J., 2002. Preliminary study on the flooding and drought calamity during past 150 yrs in the Hai' an region, Jiangsu Province. Chinese Geographical Science 12 (2),146-151.

Zhang, Q., Liu, C.L., Xu, C.Y., Xu, Y.P., T. Jiang, 2006. Observed trends of annual maximum water level and stream flow during past 130 years in the Yangtze River basin, China. Journal of Hydrology 324, 255-265.

Zhang, Q., Xu, C.Y., Becker, S. and Jiang, T., 2006. Sediment and runoff changes in the Yangtze River basin during past 50 years. Journal of Hydrology 331, 511-523.

Zhao, G.J., Mu, X.M. Hörmann, G. Fohrer, N., Xiong, M., Su B.D, Li, X.C., 2012. Spatial patterns and temporal variability of dryness/wetness in the Yangtze River Basin, China. Quaternary International 282, 5-13. 
Zheng, Y., Kissel, C., Zheng, H.B., Laj, C., Wang, K., 2010. Sedimentation on the inner shelf of the East China Sea: Magnetic properties, diagenesis and paleoclimate inplications. Marine Geology 268(1-4), 34-42.

Fig.1. Regional ocean circulation pattern in the East China Sea. Changjiang Dilute Water (CDW), Chinese Coastal Current (CCC), Zhejiang Fujian Coastal Current (ZFCC), Jiangsu Coastal Current (JCC), Yellow Sea Warm Current (YSWC), Taiwan Warm Current (TWC), Kuroshio Current (KC). The shade areas represent the mud belts located in the Yangtze River delta and the inner shelf of ECS. Fig.2. The distribution of surface sediments in the ECS (modified after Li et al., 2005; Xiao et al., 2006).

Fig.3. lithostratigraphic units of core MD06-3040. (a) lithostratigraphic unit of core MD06-3040 with AMS ${ }^{14} \mathrm{C}$ ages. (b) Magnetic susceptibility of core MD06-3040. (c) Magnetic susceptibility of core MD06-3039. (d) Sorting coefficient of core MD06-3040 grain size (e) Mean grain size of core MD06-3040. (f) Seismic profile of core MD06-3040. (g) Age model of core MD06-3040.

Fig.4. Grain size distribution of representative sediments of core MD06-3040.

Fig.5. Temporal variations of (a) linear sedimentation rate of core MD06-3040. (b) four grain size subpopulations: clay, fine silt, coarse silt and sand. (c) ESR signal intensity and (d) Crystallinity index of quartz

Fig.6. The relationship between ESR signal intensity and crystallinity index of quartz in different fractions from the core MD06-3040 and core YD09-01.

Fig.7. Comparison of core MD06-3040 records with other paleoclimate records since $10000 \mathrm{yr}$. (a) Modal grain size of fine silt fraction. (b) Coarse silt / fine silt ratio. (c) $\delta^{18} \mathrm{O}_{\mathrm{w}}$ from Core KY07-04-01 in northern ECS (Kubota et al., 2014). (d) Reconstruction of Holocene precipitation derived by comparing stalagmite calibrated $\Delta \delta^{18} \mathrm{O}_{\text {sp }}$ record in southwest China (Hu et al., 2008). Shaded bars represent lower discharge events recorded in core MD06-3040).

Table.1 Accelerator Mass Spectrometer ${ }^{14} \mathrm{C}$ ages for samples from core MD06-3039 and MD06-3040.

\begin{tabular}{|c|c|c|c|c|c|}
\hline \multirow{2}{*}{$\begin{array}{l}\text { Laboratory } \\
\text { code }\end{array}$} & \multirow{2}{*}{$\begin{array}{l}\text { Depth }(\mathrm{cm}) \\
\text { MD06-3039 }\end{array}$} & \multirow{2}{*}{$\begin{array}{l}\text { Depth }(\mathrm{cm}) \\
\text { MD06-3040 }\end{array}$} & \multirow{2}{*}{$\begin{array}{c}\text { Conventional }{ }^{14} \mathrm{C} \text { age } \\
\text { (BP) }\end{array}$} & \multicolumn{2}{|c|}{ Calibrated age (cal BP) } \\
\hline & & & & Intercept & Range \\
\hline GZ819 & $140-141$ & $(154-155)$ & $627 \pm 21$ & 275 & $257-292$ \\
\hline GZ820 & $210-211$ & $(231-232)$ & $1217 \pm 22$ & 752 & $716-783$ \\
\hline GZ821 & $282-283$ & $(310-311)$ & $1741 \pm 21$ & 1290 & $1265-1311$ \\
\hline GZ824 & $475-476$ & $(522-523)$ & $3396 \pm 22$ & 3277 & 3240-3319 \\
\hline GZ825 & $663-664$ & $(728-729)$ & $3917 \pm 25$ & 3896 & $3850-3940$ \\
\hline GZ2018 & & $1151-1152$ & $4992 \pm 34$ & 5351 & $5294-5396$ \\
\hline GZ2019 & & $1363-1364$ & $5788 \pm 41$ & 6589 & $6544-6655$ \\
\hline GZ2022 & & $1611-1612$ & $7205 \pm 36$ & 7666 & $7616-7704$ \\
\hline GZ826 & & $1912-1913$ & $9479 \pm 33$ & 10325 & 10259-10376 \\
\hline
\end{tabular}

Table.2

\begin{tabular}{ccccc}
\hline Sample ID & Depth $(\mathrm{cm})$ & Cal. Age & ESR Signal Intensity (Spin Unit) & Cl \\
\hline MD06-3040-41, 4-16 $\mu \mathrm{m}$ & 41 & 73.39 & 10.08 & 8.54 \\
MD06-3040-85, 4-16 $\mu \mathrm{m}$ & 85 & 152.15 & 10.46 & 3.87
\end{tabular}




\begin{tabular}{|c|c|c|c|c|}
\hline MD06-3040-97, 4-16 $\mu \mathrm{m}$ & 97 & 173.63 & 10.34 & 8.49 \\
\hline MD06-3040-125, 4-16 $\mu \mathrm{m}$ & 125 & 223.75 & 12.14 & 8.46 \\
\hline MD06-3040-165, 4-16 $\mu \mathrm{m}$ & 165 & 343.15 & 5.65 & 8.25 \\
\hline MD06-3040-173, 4-16 $\mu \mathrm{m}$ & 173 & 392.71 & 9.15 & 8.11 \\
\hline MD06-3040-201, 4-16 بm & 201 & 566.17 & 11.82 & 8.55 \\
\hline MD06-3040-265, 4-16 $\mu \mathrm{m}$ & 265 & 983.54 & 9.94 & 8.73 \\
\hline MD06-3040-273, 4-16 $\mu \mathrm{m}$ & 273 & 1038.02 & 8.89 & 8.24 \\
\hline MD06-3040-281, 4-16 بm & 281 & 1092.50 & 7.60 & 8.34 \\
\hline MD06-3040-293, 4-16 $\mu \mathrm{m}$ & 293 & 1174.22 & 7.84 & 8.48 \\
\hline MD06-3040-301, 4-16 $\mu \mathrm{m}$ & 301 & 1228.70 & 8.85 & 8.19 \\
\hline MD06-3040-333, 4-16 $\mu \mathrm{m}$ & 333 & 1505.51 & 6.24 & 8.37 \\
\hline MD06-3040-353, 4-16 $\mu \mathrm{m}$ & 353 & 1692.91 & 5.78 & 8.56 \\
\hline MD06-3040-373, 4-16 $\mu \mathrm{m}$ & 373 & 1880.31 & 18.63 & 8.31 \\
\hline MD06-3040-393, 4-16 $\mu \mathrm{m}$ & 393 & 2067.71 & 7.52 & 8.22 \\
\hline MD06-3040-401, 4-16 $\mu \mathrm{m}$ & 401 & 2142.67 & 7.24 & 8.44 \\
\hline MD06-3040-425, 4-16 $\mu \mathrm{m}$ & 425 & 2367.55 & 7.54 & 8.01 \\
\hline MD06-3040-473, 4-16 $\mu \mathrm{m}$ & 473 & 2817.31 & 8.10 & 8.55 \\
\hline MD06-3040-501, 4-16 $\mu \mathrm{m}$ & 501 & 3079.67 & 5.25 & 8.27 \\
\hline MD06-3040-577, 4-16 $\mu \mathrm{m}$ & 577 & 3442.00 & 12.62 & 8.57 \\
\hline MD06-3040-617, 4-16 $\mu \mathrm{m}$ & 617 & 3562.00 & 6.36 & 8.56 \\
\hline MD06-3040-661, 4-16 $\mu \mathrm{m}$ & 661 & 3694.00 & 14.79 & 8.39 \\
\hline MD06-3040-669, 4-16 $\mu \mathrm{m}$ & 669 & 3718.00 & 9.01 & 8.35 \\
\hline MD06-3040-681, 4-16 $\mu \mathrm{m}$ & 681 & 3754.00 & 8.83 & 8.12 \\
\hline MD06-3040-741, 4-16 $\mu \mathrm{m}$ & 741 & 3940.72 & 12.06 & 8.38 \\
\hline MD06-3040-825, 4-16 $\mu \mathrm{m}$ & 825 & 4229.68 & 17.18 & 8.67 \\
\hline MD06-3040-837, 4-16 $\mu \mathrm{m}$ & 837 & 4270.96 & 9.66 & 8.56 \\
\hline MD06-3040-885, 4-16 $\mu \mathrm{m}$ & 885 & 4436.08 & 9.87 & 8.05 \\
\hline MD06-3040-953, 4-16 $\mu \mathrm{m}$ & 953 & 4670.00 & 9.79 & 8.30 \\
\hline MD06-3040-965, 4-16 $\mu \mathrm{m}$ & 965 & 4711.28 & 7.88 & 8.43 \\
\hline MD06-3040-1029, 4-16 $\mu \mathrm{m}$ & 1029 & 4931.44 & 10.91 & 8.24 \\
\hline MD06-3040-1057, 4-16 $\mu \mathrm{m}$ & 1057 & 5027.76 & 9.01 & 8.46 \\
\hline MD06-3040-1085, 4-16 $\mu \mathrm{m}$ & 1085 & 5124.08 & 9.17 & 8.02 \\
\hline MD06-3040-1121, 4-16 $\mu \mathrm{m}$ & 1121 & 5247.92 & 9.54 & 8.43 \\
\hline MD06-3040-1133, 4-16 $\mu \mathrm{m}$ & 1133 & 5289.20 & 23.98 & 8.16 \\
\hline MD06-3040-1169, 4-16 $\mu \mathrm{m}$ & 1169 & 5455.94 & 9.36 & 8.27 \\
\hline MD06-3040-1229, 4-16 $\mu \mathrm{m}$ & 1229 & 5805.74 & 7.48 & 8.30 \\
\hline MD06-3040-1381, 4-16 $\mu \mathrm{m}$ & 1381 & 6667.12 & 23.71 & 8.20 \\
\hline MD06-3040-1497, 4-16 $\mu \mathrm{m}$ & 1497 & 7170.56 & 15.97 & 7.80 \\
\hline MD06-3040-1585, 4-16 $\mu \mathrm{m}$ & 1585 & 7552.48 & 10.59 & 8.32 \\
\hline MD06-3040-1601, 4-16 $\mu \mathrm{m}$ & 1601 & 7621.92 & 11.78 & 8.46 \\
\hline MD06-3040-1633, 4-16 $\mu \mathrm{m}$ & 1633 & 7860.35 & 16.65 & 3 \\
\hline MD06-3040-1665, 4-16 $\mu \mathrm{m}$ & 1665 & 8143.04 & 12.76 & 8.30 \\
\hline MD06-3040-1709, 4-16 $\mu \mathrm{m}$ & 1709 & 8531.73 & 3.76 & 8.09 \\
\hline MD06-3040-1729, 4-16 $\mu \mathrm{m}$ & 1729 & 8708.41 & 8.95 & .27 \\
\hline
\end{tabular}




\begin{tabular}{|c|c|c|c|c|}
\hline MD06-3040-1765, 4-16 $\mu \mathrm{m}$ & 1765 & 9026.44 & 10.04 & 7.76 \\
\hline MD06-3040-1773, 4-16 $\mu \mathrm{m}$ & 1773 & 9097.11 & 9.16 & 7.66 \\
\hline MD06-3040-1833, 4-16 $\mu \mathrm{m}$ & 1833 & 9627.15 & 13.65 & 8.01 \\
\hline MD3040-5, 16-63 $\mu \mathrm{m}$ & 5 & 8.95 & 5.01 & 7.96 \\
\hline MD3040-41, 16-63 $\mu \mathrm{m}$ & 41 & 73.39 & 11.35 & 7.53 \\
\hline MD3040-85, 16-63 $\mu \mathrm{m}$ & 85 & 152.15 & 13.36 & 7.83 \\
\hline 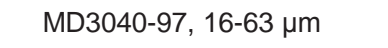 & 97 & 173.63 & 9.60 & 8.00 \\
\hline MD3040-125, 16-63 $\mu \mathrm{m}$ & 125 & 223.75 & 7.08 & 8.07 \\
\hline MD3040-165, 16-63 $\mu \mathrm{m}$ & 165 & 343.15 & 6.97 & 7.90 \\
\hline MD3040-201 , 16-63 $\mu \mathrm{m}$ & 201 & 566.17 & 8.00 & 8.60 \\
\hline MD3040-273, 16-63 $\mu \mathrm{m}$ & 273 & 1038.02 & 4.99 & 8.17 \\
\hline MD3040-293, 16-63 $\mu \mathrm{m}$ & 293 & 1174.22 & 5.15 & 8.29 \\
\hline MD3040-297 , 16-63 $\mu \mathrm{m}$ & 297 & 1201.46 & 4.10 & 8.56 \\
\hline MD3040-301 , 16-63 $\mu \mathrm{m}$ & 301 & 1228.70 & 7.69 & 8.56 \\
\hline MD3040-321 , 16-63 $\mu \mathrm{m}$ & 321 & 1393.07 & 6.69 & 8.51 \\
\hline MD3040-333 , 16-63 $\mu \mathrm{m}$ & 333 & 1505.51 & 6.08 & 8.32 \\
\hline MD3040-353 , 16-63 $\mu \mathrm{m}$ & 353 & 1692.91 & 11.94 & 8.00 \\
\hline MD3040-373, 16-63 $\mu \mathrm{m}$ & 373 & 1880.31 & 7.65 & 7.83 \\
\hline MD3040-401 , 16-63 $\mu \mathrm{m}$ & 401 & 2142.67 & 8.35 & 7.51 \\
\hline MD3040-425, 16-63 $\mu \mathrm{m}$ & 425 & 2367.55 & 7.54 & 8.02 \\
\hline MD3040-473 , 16-63 $\mu \mathrm{m}$ & 473 & 2817.31 & 8.68 & 7.98 \\
\hline MD3040-501 , 16-63 $\mu \mathrm{m}$ & 501 & 3079.67 & 7.88 & 8.63 \\
\hline MD3040-545, 16-63 $\mu \mathrm{m}$ & 545 & 3346.00 & 11.17 & 7.02 \\
\hline MD3040-577 , 16-63 $\mu \mathrm{m}$ & 577 & 3442.00 & 8.33 & 7.99 \\
\hline MD3040-661 , 16-63 $\mu \mathrm{m}$ & 661 & 369400 & 8.68 & 8.45 \\
\hline MD3040-669, 16-63 $\mu \mathrm{m}$ & 669 & 3718.00 & 8.36 & 7.93 \\
\hline MD3040-769 , 16-63 $\mu \mathrm{m}$ & 769 & 4037.04 & 7.80 & 8.47 \\
\hline MD3040-789 , 16-63 $\mu \mathrm{m}$ & 789 & 4105.84 & 4.38 & 8.33 \\
\hline MD3040-825 , 16-63 $\mu \mathrm{m}$ & 825 & 4229.68 & 9.95 & 8.28 \\
\hline MD3040-837 , 16-63 $\mu \mathrm{m}$ & 837 & 4270.96 & 7.44 & 8.36 \\
\hline MD3040-877 , 16-63 $\mu \mathrm{m}$ & 877 & 4408.56 & 8.91 & 8.13 \\
\hline MD3040-1029 , 16-63 $\mu \mathrm{m}$ & 1029 & 4931.44 & 9.13 & 7.21 \\
\hline MD3040-1153, 16-63 $\mu \mathrm{m}$ & 1153 & 5362.66 & 6.32 & 7.43 \\
\hline MD3040-1229 , 16-63 $\mu \mathrm{m}$ & 1229 & 5805.74 & 5.82 & 7.96 \\
\hline MD3040-1285, 16-63 $\mu \mathrm{m}$ & 1285 & 6132.22 & 8.86 & 7.97 \\
\hline MD3040-1381 , 16-63 $\mu \mathrm{m}$ & 1381 & 6667.12 & 7.00 & 7.96 \\
\hline MD3040-1633 , 16-63 $\mu \mathrm{m}$ & 1633 & 7860.35 & 6.92 & 8.35 \\
\hline MD3040-1709, 16-63 $\mu \mathrm{m}$ & 1709 & 8531.73 & 10.19 & 8.10 \\
\hline MD3040-1765, 16-63 $\mu \mathrm{m}$ & 1765 & 9026.44 & 6.75 & 7.93 \\
\hline MD3040-1833 , 16-63 $\mu \mathrm{m}$ & 1833 & 9627.15 & 5.91 & 7.97 \\
\hline Min River, 16-63 $\mu \mathrm{m}$ & & & 5.33 & 9.32 \\
\hline Modern Yellow River, 16-63 $\mu \mathrm{m}$ & & & 12.45 & 8.07 \\
\hline Ou River, 16-63 $\mu \mathrm{m}$ & & & 23.08 & 7.83 \\
\hline Qian Tang River, 16-63 $\mu \mathrm{m}$ & & & 19.53 & 8.09 \\
\hline
\end{tabular}


Eigure 1

Click here to download high resolution image

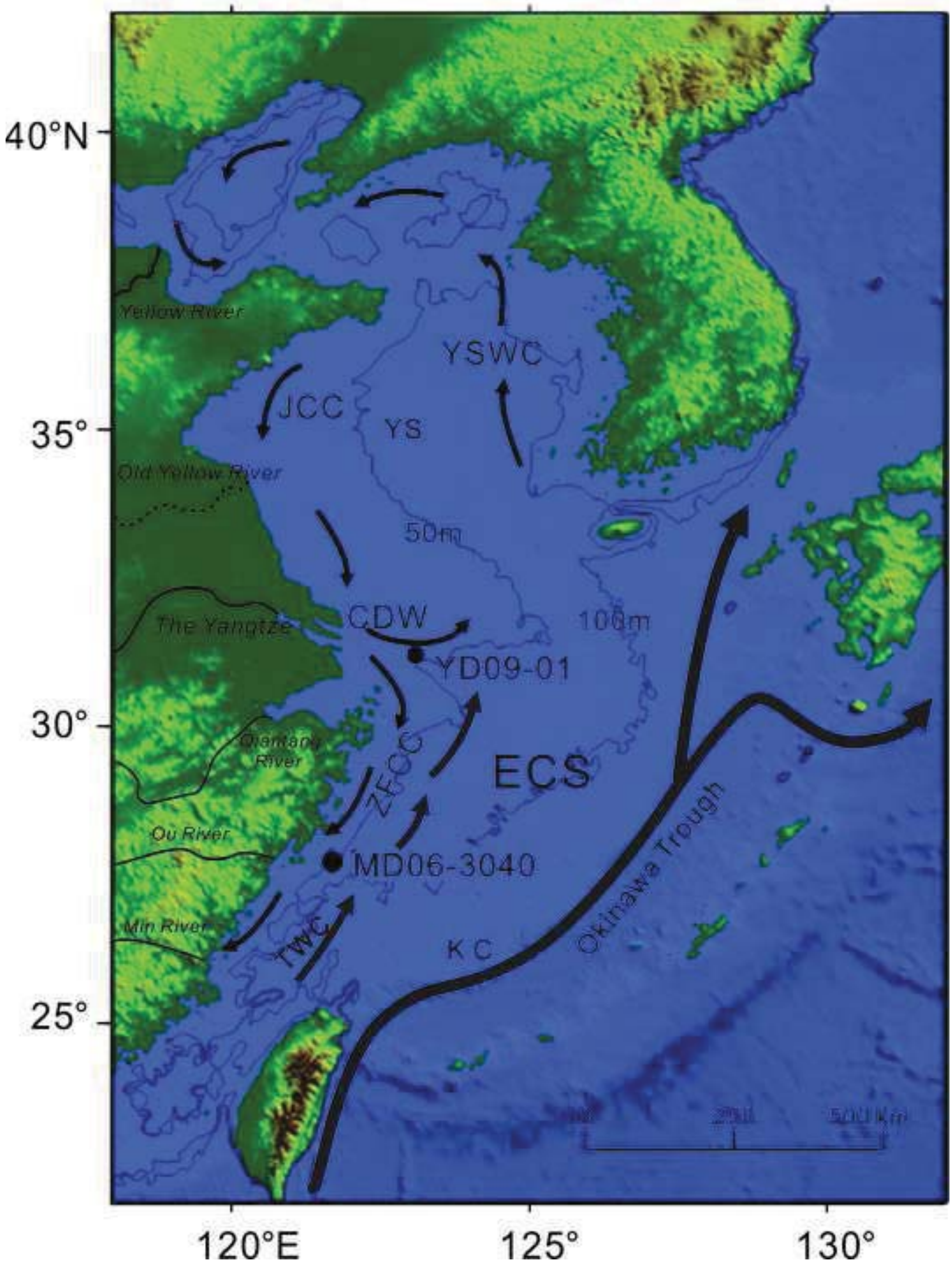




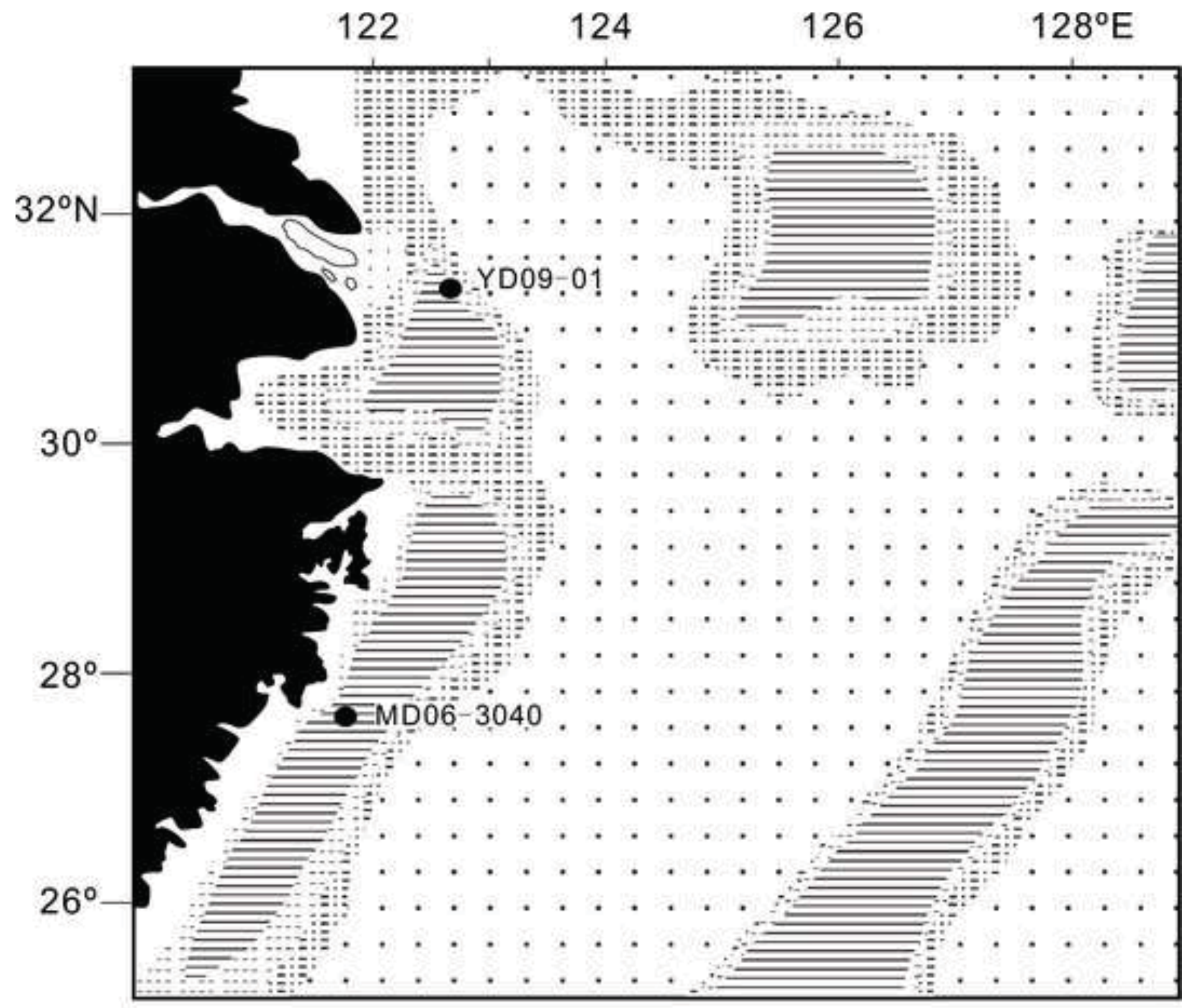

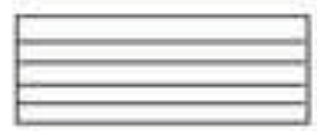

Clay

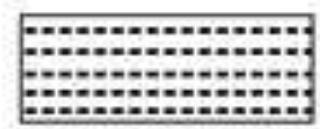

Silty clay

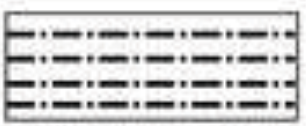

Clayey silt

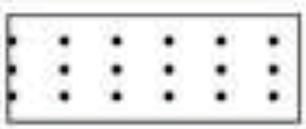

Sand 


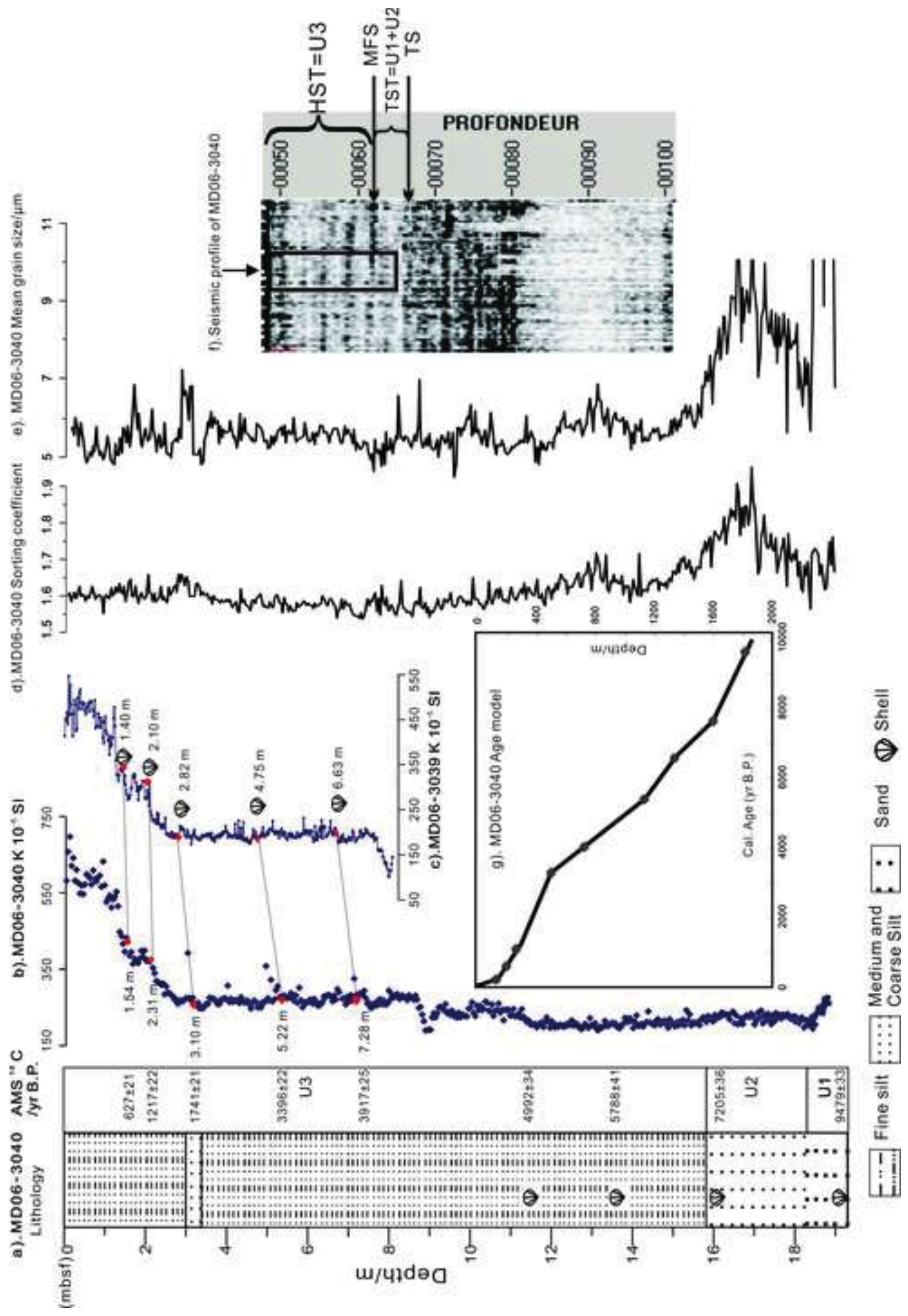


click here to download high resolution image
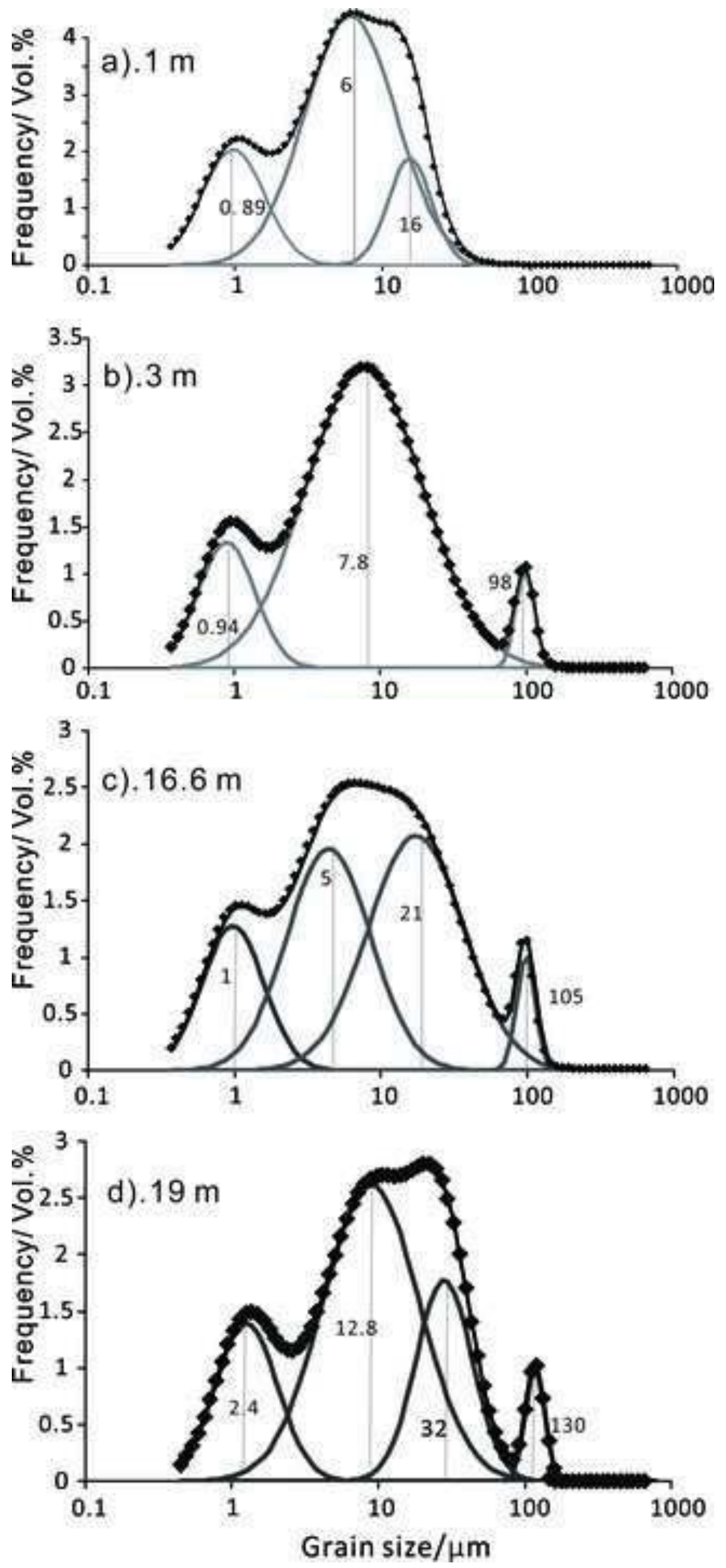
Figure 5

Click here to download high resolution image

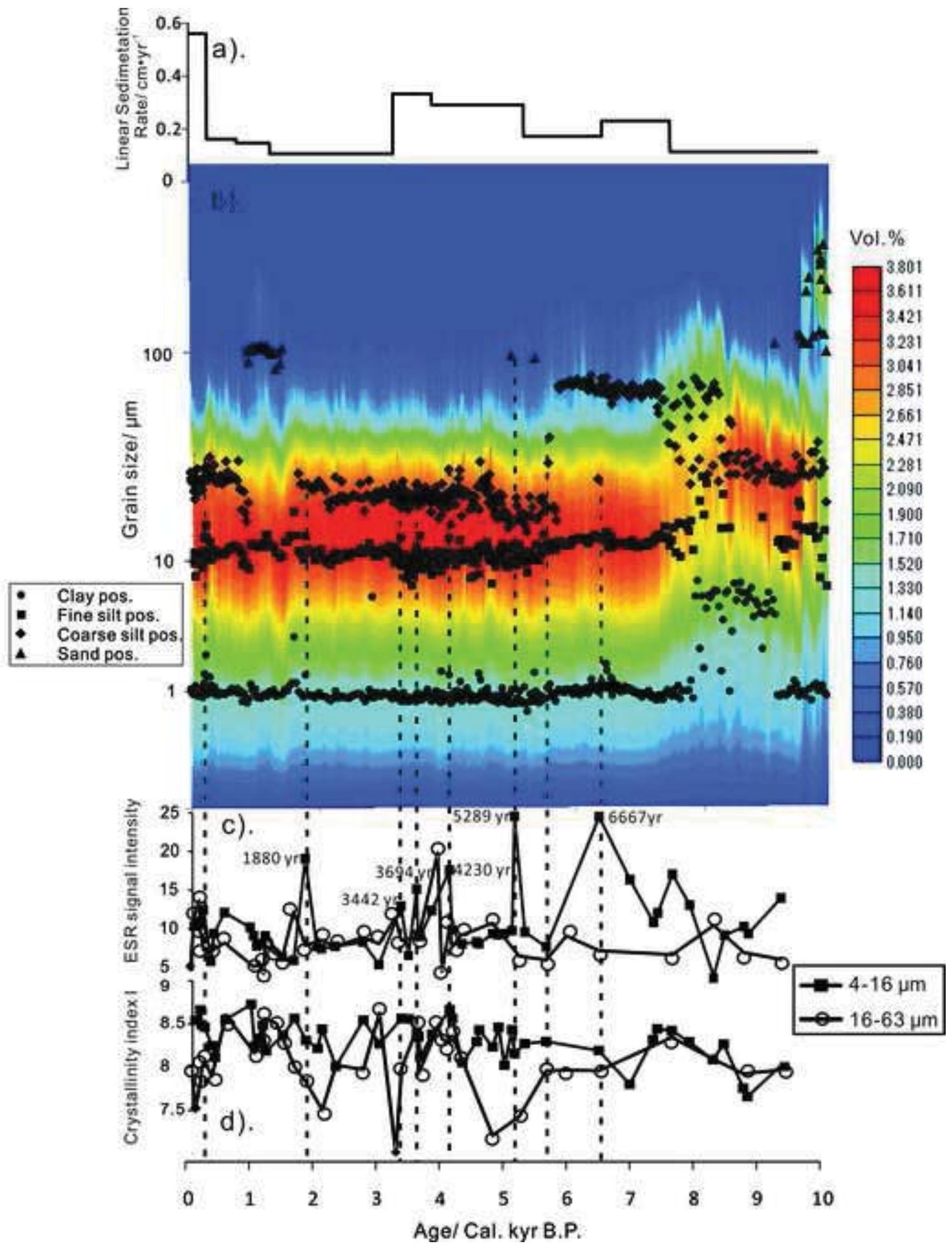



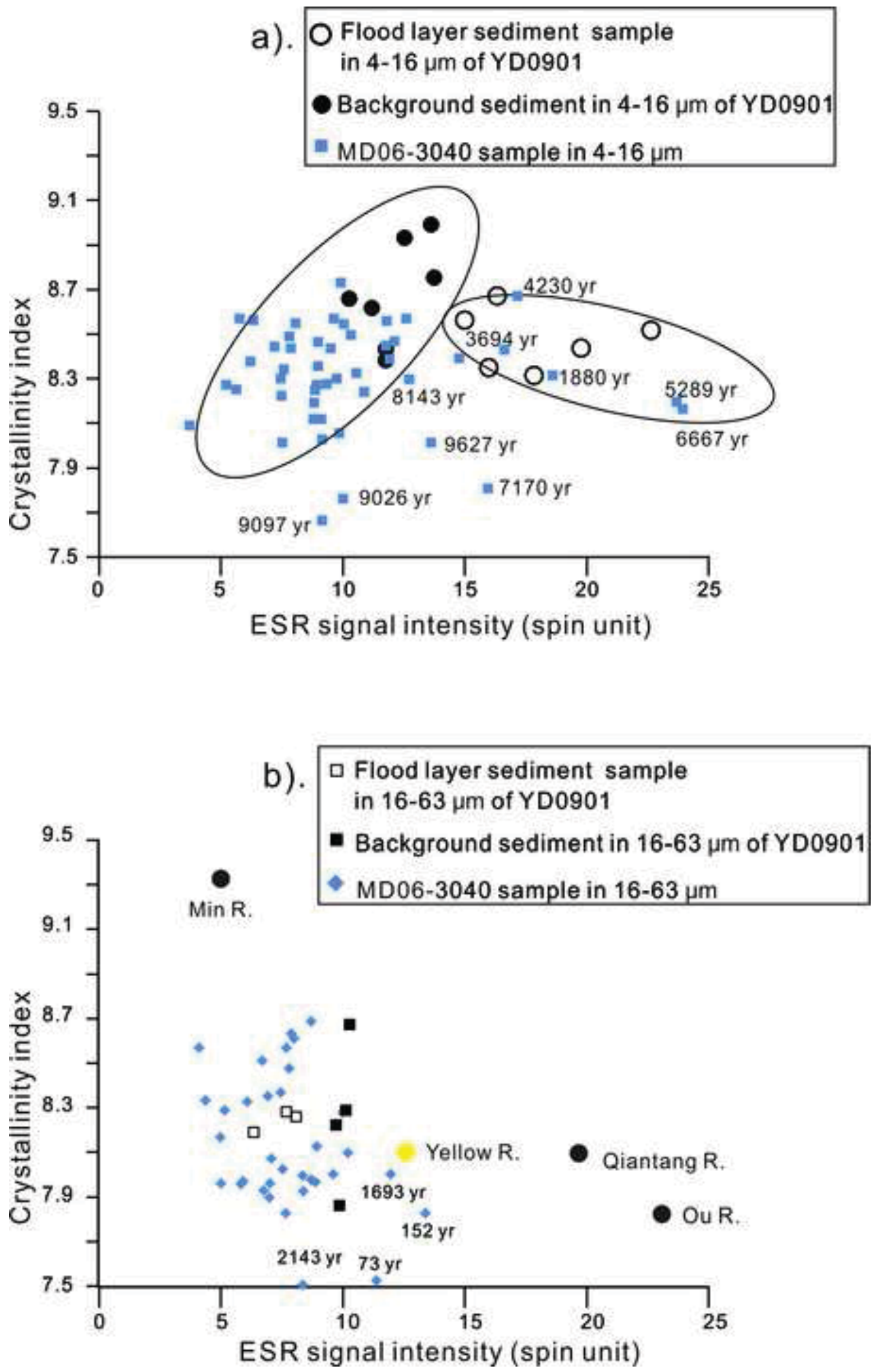


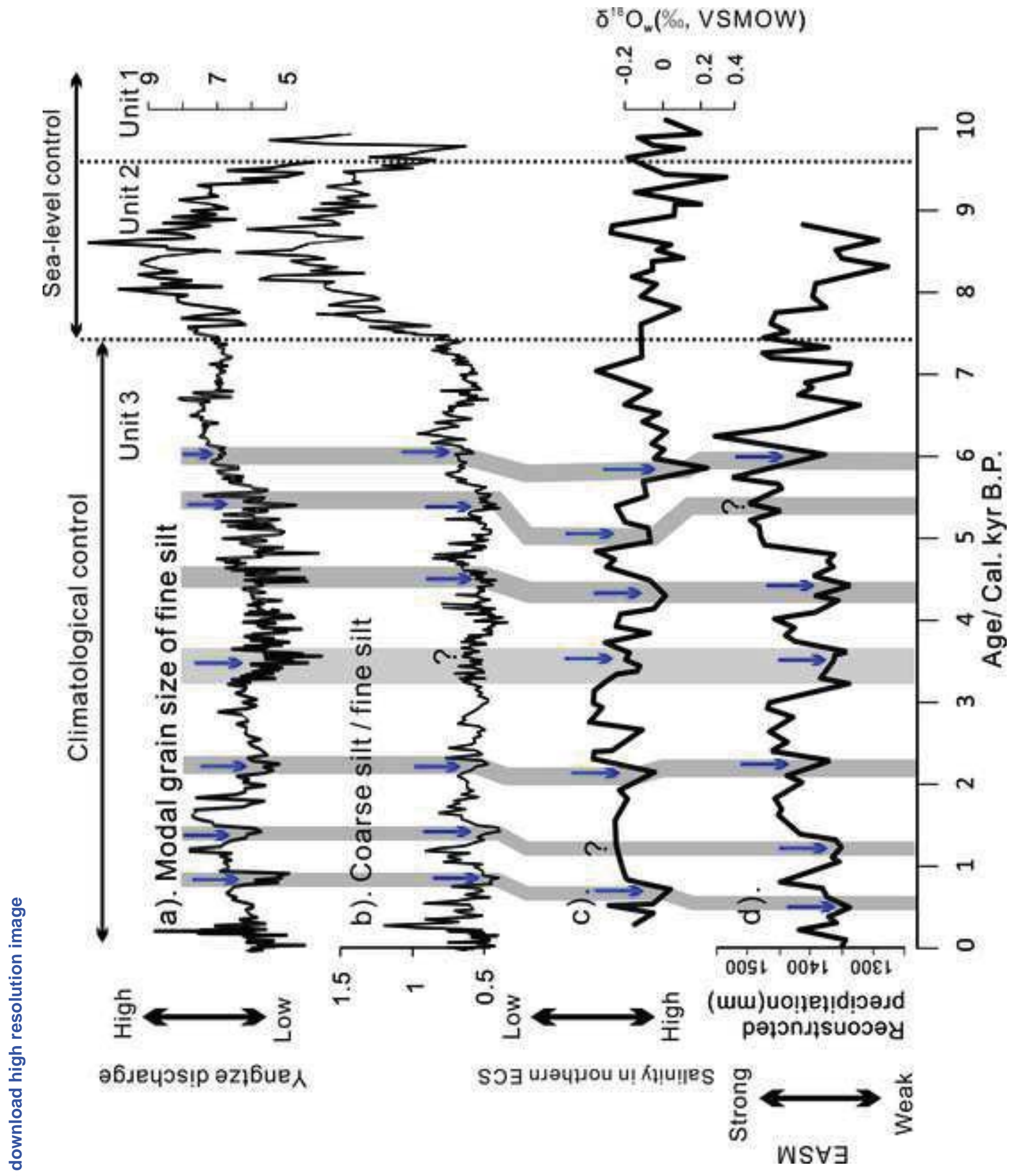

